\title{
Deficiency in protein tyrosine phosphatase PTP1B shortens lifespan and leads to development of
} acute leukemia

Samantha Le Sommer ${ }^{1}$, Nicola Morrice ${ }^{1}$, Martina Pesaresi ${ }^{1}$, Dawn Thompson ${ }^{1}$, Mark A. Vickers ${ }^{1}$, Graeme I. Murray ${ }^{1}$, Nimesh Mody ${ }^{1}$, Benjamin G Neel ${ }^{2}$, Kendra K Bence ${ }^{3,4}$, Heather M Wilson ${ }^{1 *}$, \& Mirela Delibegovic ${ }^{1 *}$

${ }^{1}$ Institute of Medical Sciences, University of Aberdeen, United Kingdom

${ }^{2}$ Laura and Isaac PerImutter Cancer Center, New York University Langone Medical Center, New York University, New York, New York 10016, USA.

${ }^{3}$ Dept. of Biomedical Sciences, University of Pennsylvania School of Veterinary Medicine, Philadelphia, USA.

${ }^{4}$ Current address: Internal Medicine Research Unit (IMRU), Pfizer Inc, 610 Main St.

Cambridge, MA 02139 USA

*corresponding authors: Prof. Mirela Delibegovic (m.delibegovic@abdn.ac.uk) and Dr. Heather Wilson (h.m.wilson@abdn.ac.uk )

Running Title: PTP1B deficiency shortens lifespan and leads to leukaemia

Key Words: PTP1B, lifespan, leukaemia, myeloid, STAT3

Additional information: This work was performed with the funds from the Wellcome Trust ISSF grant to M. Delibegovic and BHF project grant to M. Delibegovic (PG/11/8/28703). S. Le Sommer is a recipient of the University of Aberdeen Institute of Medical Sciences PhD studentship.

Conflict of interest: Authors declare there are no conflicts of interests.

Word Count: 5,000

Figure Count: 6 Figures, 1 Table (Supplemental Figures: 6, Supplemental Tables: 4) 


\section{Abstract:}

Protein tyrosine phosphatase PTP1B is a critical regulator of signaling pathways controlling metabolic homeostasis, cell proliferation and immunity. In this study, we report that global or myeloid-specific deficiency of PTP1B in mice decreases lifespan. We demonstrate that myeloidspecific deficiency of PTP1B is sufficient to promote the development of acute myeloid leukemia (AML). LysM-PTP1B-/- mice lacking PTP1B in the innate myeloid cell lineage displayed a dysregulation of bone marrow cells with a rapid decline in population at midlife and a concomitant increase in peripheral blood blast cells. This phenotype manifested further with extramedullary tumors, hepatic macrophage infiltration and metabolic reprogramming, suggesting increased hepatic lipid metabolism prior to overt tumor development. Mechanistic investigations revealed an increase in anti-inflammatory M2 macrophage responses in liver and spleen, as associated with increased expression of arginase I and the cytokines IL-10 and IL-4. We also documented STAT3 hypersphosphorylation and signaling along with JAK-dependent upregulation of anti-apoptotic proteins Bcl2 and BcIXL. Our results establish a tumor suppressor role for PTP1B in the myeloid lineage cells, with evidence that its genetic inactivation in mice is sufficient to drive acute myeloid leukemia. 


\section{Introduction}

Protein tyrosine phosphatase 1B (PTP1B) is a non-receptor tyrosine-phosphatase that plays critical roles in a number of signalling cascades, notably insulin signalling, where it directly dephosphorylates the insulin receptor (1),(2). Consequently, it has been identified as an attractive drug target for the treatment of type 2 diabetes mellitus (T2DM) and obesity. PTP1B inhibitors are currently in phase II clinical trials for T2DM treatment, as both PTP1B inhibition and genetic ablation improve glucose homeostasis and promote weight loss $(3),(4,5)$. New substrates for the enzyme continue to be identified, but recent evidence has shown it plays a critical role in the regulation of inflammation, cell proliferation, differentiation and invasion, supporting its use as a therapeutic target for inflammatory and autoimmune diseases and cancer (6).

Whilst global PTP1B knockout $\left(\mathrm{PTP}^{-\mathrm{B}^{-/}}\right)$mice exhibited resistance to diet-induced obesity and insulin resistance (1),(2), they also showed a higher rate of death when challenged with highdose lipopolysaccharide (LPS) injections (7), and an enhanced response to irradiation, when challenged with LPS and D-galactosamine (8). These studies suggest a critical role for macrophage PTP1B in regulation of immune responses.

Mice lacking PTP1B in the myeloid cell lineage specifically (LysM-PTP1B ${ }^{-1}$ ), also exhibited improved glucose homeostasis and protection against high-fat diet induced inflammation and lipopolysaccharide (LPS) induced endotoxemia, via an interleukin-10 (IL-10) - signal transducer and activation of transcription 3 (STAT3) dependent mechanism (9). This was further confirmed by a transcriptomic study, which illustrated macrophage-PTP1B as a key regulator of IL-10 signalling via STAT3 (10).

We recently provided the first evidence for a major regulatory role of PTP1B in dendritic cells (DC); PTP1B-deficient DC exhibited hyper-phosphorylation of STAT3, even under basal conditions. DC-PTP1B inhibition resulted in decreased migration, increased IL-10 secretion and a decreased ability to prime adaptive immune responses (11). 
It has been shown previously that PTP1B plays a key role in the pathogenesis of tumour development. Overexpression of PTP1B can be a driving factor in the pathogenesis of breast cancer $(6,12)$, whereas deficiency has been shown to increase the invasiveness of prostate cancer (13). STAT3 over-expression and/or over-activation also plays a critical role in multiple tumorigenic processes (14). Deletion of chromosome 20q (del(20q)) is a common chromosomal abnormality associated with myeloid neoplasms and the del(20q) involving PTPN1 deletion was observed in $8 \%$ of secondary acute myeloid leukaemia cases and $17 \%$ of myeloproliferative neoplasms. Given the poorly defined and often opposing roles that PTP1B and STAT3 play in the aetiology of inflammation and cancers, we sought to characterise the long-term implications of PTP1B deficiency and associated STAT3 hyperphosphorylation in myeloid cells that drive the pathogenesis of both conditions.

We report here that the absence of myeloid PTP1B (LysM-PTP1B ${ }^{-1}$ ) in mice results in a shortened lifespan due to the late development of acute leukaemia. By contrast, heterozygous deficiency (LysM-PTP1B ${ }^{+/}$) does not lead to development of leukaemia, suggestive that a complete deficiency of PTP1B is required for the phenotype. This recapitulates the shortened lifespan we observe in global PTP1B ${ }^{-/-}$mice. 


\section{Methods:}

\section{Animal Studies:}

All animal procedures were approved by the UK Home Office under The Animals (Scientific Procedures) Act 1986 (PPL60/3951). PTP1B ${ }^{-/-}$and wild type PTP1B ${ }^{+/+}$littermates were maintained for lifespan studies at Beth Israel Deaconess Medical Center, Boston, USA (2). PTP1B ${ }^{\mathrm{fl} / \mathrm{fl}}$ mice (15) and mice expressing Cre under the LysM-promotor (LysM-PTP1B ${ }^{-1-}$ ) (16) were maintained for lifespan studies at the Medical Research Facility, Aberdeen, UK. Mice were housed and maintained at 22$24^{\circ} \mathrm{C}$ on a 12 hour light-dark cycle, with free access to food and water on standard chow diet and aged to 24 months (104 weeks).

\section{Bone Marrow Derived Macrophage (BMDM) preparation and treatment}

BMDM were prepared from mononuclear phagocyte precursors flushed from femurs and tibias as previously described (9). BMDM were stimulated with either $100 \mathrm{ng} / \mathrm{ml}$ lipopolysaccharide (LPS) (InvivoGen) or $20 \mathrm{ng} / \mathrm{ml} \mathrm{IL-10} \mathrm{(Peprotech).} \mathrm{In} \mathrm{selected} \mathrm{experiments,} \mathrm{mature} \mathrm{BMDM} \mathrm{were} \mathrm{pre-}$ treated with 5uM of Ruxolitinib (Selleck) before stimulation with LPS.

\section{Adhesion Assays:}

Adhesion assays were performed as previously described (17). In brief, 96-well plates were precoated with $50 \mu \mathrm{g} / \mathrm{ml}$ collagen. BMDM $\left(5 \times 10^{5}\right.$ per well) were seeded and left to adhere for 30 minutes. Non-adherent cells were washed off; adherent cells stained with crystal violet, washed and lysed. OD595 value was measured in a plate reader OpsysMR (DYNEX Technologies).

\section{Antigen presentation assays:}

We used an OVA-peptide system, which assesses the presentation of the SIINFEKL OVA-peptide on MHC class I to the T cell reporter cell line B3Z. Mature BMDM were seeded in triplicates in 96-well plates ( $5 \times 10^{4}$ cells per well). Cells were left to adhere and incubated with the SIINFEKL peptide for 
6 hours; washed with PBS, fixed with $0.05 \%$ glutaraldehyde, and quenched with $0.2 \mathrm{M}$ glycine. Cells were washed and incubated with $5 \times 10^{4}$ the CD8 T cell hybridoma cell line, B3Z for 16 hours. Stimulation of the B3Z hybridoma (18) was measured by a luminescent $\beta$-galactosidase assay (Clontech).

\section{ELISA:}

Serum and media supernatant, tumour necrosis factor alpha (TNF $\alpha$ ) and interleukin-10 (IL-10) were determined using ELISA (R\&D Systems).

\section{Differential Blood Counts:}

Blood smears were prepared and fixed in methanol then stained with eosin and methylene blue. Slides were mounted using aqueous media and visualized using light microscopy (Carl Zeiss) and AxioVision 4.8 digital image processing software (Carl Zeiss). To count reticulocytes, an oil 100x objective was used and 1000 cells counted.

\section{Flow Cytometry:}

Single-cell suspensions were prepared from spleens and red blood cells lysed for 1 minute with lysis buffer (Sigma Aldrich). Fc receptor binding sites were blocked with rat anti-mouse CD16/CD32 (BD Cat: 553141, $0.5 \mathrm{mg} /$ reaction) and cells labelled with: PE Rat Anti-Mouse CD45R/B220 (BD Pharmingen); Alexa Fluor ${ }^{\circledR} 700$ Rat Anti-Mouse F4/80 (Biolegend ${ }^{\circledR}$ ); PE-CF594 Rat Anti-Mouse CD11b (BD Horizon); V450 Rat Anti-Mouse CD8a (BD Horizon ${ }^{\mathrm{TM}}$ ); Alexa Fluor ${ }^{\circledR} 488$ Hamster Anti-Mouse CD3e (BD Pharmingen); PerCP-CyTM5.5 Rat Anti-Mouse CD4 (BD Pharmingen); PE Rat Anti-Mouse CD25 (BD Pharmingen). Data were acquired on a BD Fortessa and analysed using FlowJo.

\section{Haematocrit:}

Fresh blood was drawn into two heparinized capillary tubes. Samples were spun in a microhematocrit centrifuge and packed cell volume measured and percentages calculated.

\section{White Blood Cell Count:}

Whole blood was diluted in 5 volumes of RBC lysing buffer (Sigma Aldrich). White blood cells were counted using an automated Becton Coulter Z2 cell counter. 


\section{Haematoxylin and Eosin Staining:}

Tissues were fixed in formaldehyde, embedded in paraffin, sectioned and stained with haematoxylin and eosin. Histological analysis on H\&E stained sections was performed by an experienced histopathologist (MV).

\section{Immunoblotting:}

Tissues and cells were homogenized in radioimmunoprecipitation-assay buffer containing sodiumorthovanadate and protease inhibitors (9). Proteins were separated by SDS-PAGE (4-12\%) and transferred to nitrocellulose. Immunoblotting was performed using antibodies from Cell Signalling Technologies, unless otherwise stated: p-STAT3 Y705, p-STAT3 S727, STAT3, p-P38 T108/Y182, P38, p-ERK T202/204, ERK, GAPDH, pSTAT5 Y694, STAT5 and PTP1B (Millipore). Immunoblots were visualized using enhanced chemilluminescence, and quantified using Bio-1D densitometry scanning software (PeqLab, UK).

\section{Immunohistochemistry:}

Immunohistochemistry was performed as previously described (9). Briefly, tissues were fixed in formalin, embedded in paraffin, sectioned, dewaxed in Histoclear, rehydrated, subjected to antigen retrieval (10mM Trisodium Citrate $\mathrm{HCl}, \mathrm{pH} 6,0.05 \%(\mathrm{v} / \mathrm{v})$ Tween), quenched and blocked (TBS-Tween, $0.05 \%(v / v)$ Goat Serum). Primary antibody was incubated at optimal concentration followed by secondary HRP-conjugated antibody. DAB substrate was used for detection with a haematoxylin nuclear counterstain. Sections were visualized by light microscopy (Carl Zeiss Microscopy) and AxioVision 4.8 digital image processing software (Carl Zeiss Microscopy).

\section{Gene Expression Analysis:}

Tissues were homogenized in TriZol reagent (Sigma) and cDNA synthesis carried out from $1 \mu \mathrm{g}$ of RNA using a Tetro cDNA Synthesis Kit (Bioline). Quantitative PCR was performed using a Light Cycler 480 (Roche) and gene expression of $f 4 / 80, c d 11 b, c d 68$, arginase, il-4, il-6, il-10, stat3, stat5, bcl-2, bcl-6, bcl-x, Fas, Hgf, Myc, Nfe212,Hdec4 and Fos, were determined in relation to the most stable housekeeping gene (either ywhaz or nono). Primer sequences are available in supplemental data. 


\section{ChIP-seq analysis:}

Detailed description can be found in Supplemental Methods. BMDM extracted from PTP1B ${ }^{\mathrm{fl} / \mathrm{fl}}$ and LysM-PTP1B ${ }^{-/}$mice aged 6 months were treated \pm IL10 20ng/ml (Peprotech) for 4 hours(n=4/group). ChIP was performed using the SimpleChIP Enzymatic Chromatin IP kit (Cell Signalling) according to manufacturer's instructions, with chromatin sheered to $200 \mathrm{bp}$ and $10 \mu \mathrm{l}$ of STAT3 Mouse mAb \#9139 per IP (Cell Signalling).

\section{Microarray bioinformatics analysis:}

Detailed description can be found in Supplemental Methods. PTP1B ${ }^{\mathrm{fl} / \mathrm{fl}}$ and LysM-PTP1B ${ }^{-/-}$mice $(\mathrm{n}=5$ and 4, respectively) were injected with $0.5 \mathrm{mg} / \mathrm{kg}$ LPS i.p. for 3 hours. Microarray was performed using Gene 2.0ST array (Affymetrix), according to manufacturer's instructions.

\section{Data Analysis:}

Data are expressed as mean \pm SEM unless otherwise stated. Statistical analyses were conducted using one-way ANOVAs with Turkey post-hoc testing, two-way ANOVAs with Bonferroni post-hoc testing, two-tailed Student's t tests, or Kaplan-Meier analyses, as appropriate, using GraphPad Prism 5 software. 


\section{Results:}

\section{Global and myeloid cell-specific PTP1B deficiency in mice shortens their lifespan}

To determine the effects of global PTP1B deficiency on lifespan, mice deficient in PTP1B globally $\left(\right.$ PTP1B $\left.^{-1-}\right)$ and wild type controls $\left(\right.$ PTP1B $\left.^{+/+}\right)$male $(n=40$ vs $n=22$, respectively) and female ( $n=23$ vs $n=17$, respectively) littermates were left undisturbed until the time of death (Supplemental Figure 1a\&b), at Beth Israel Deaconess Medical Center animal facility. Global PTP1B ${ }^{-/}$mice exhibited significantly decreased survival times, with a median survival time of 64.6 weeks in female, and 76.4 weeks in male, global PTP1B ${ }^{-/-}$mice $(p<0.0001)$ (Supplemental Tables 1-3). At the conclusion of the study at 104-weeks, the female wild type $\mathrm{PTP}^{\mathrm{B}}{ }^{+/+}$mice had reached a median survival time of 90 weeks, whilst the male $\mathrm{PTP}^{+/+}$mice remained healthy. Global PTP1B ${ }^{-/-}$mice exhibited splenomegaly (Supplemental Figure 1c-e), associated with excessive haematopoiesis in the spleen and liver, neutrophil invasion and liver necrosis.

To determine if the shortened lifespan observed in global PTP1B ${ }^{-/}$mice is due to myeloidPTP1B deficiency, given the pivotal role of PTP1B in regulating functions of myeloid cells (9), we conducted at the Medical Research Facility, University of Aberdeen, an ageing study to 104-weeks of age, comparing mice that have PTP1B deleted specifically in myeloid cells (LysM-PTP1B ${ }^{-1}$ ), mice heterozygous for myeloid PTP1B (LysM-PTP1B ${ }^{+/}$) and control littermate PTP1B $\mathrm{B}^{\mathrm{fl} / \mathrm{fl}}$ mice expressing wild type level of PTP1B ( $n=12 /$ genotype).

LysM-PTP1B ${ }^{-1-}$ mice exhibited a dramatically decreased median survival time and a shortened lifespan in comparison to PTP1B ${ }^{\mathrm{fl} / \mathrm{fl}}$ mice and LysM-PTP1B $^{+-}$mice (median survival 76 weeks), as demonstrated by Kaplan-Meier analysis of survival (Figure 1a). LysM-PTP1B $^{-/}$mice exhibited spontaneous development of extranodal tumours at approximately 40 weeks ( \pm 6.9 weeks SEM), accompanied by swollen abdomen due to splenomegaly. LysM-PTP1B ${ }^{+/-}$lifespans were shorter than

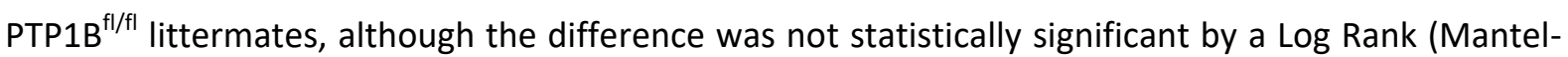
Cox) test $(\mathrm{p}=0.056)$ (Supplemental Tables $1-3)$. 
To confirm that the phenotype was dependent on the extent of myeloid-PTP1B deficiency, PTP1B expression in bone-marrow-derived-macrophages (BMDM) was determined. LysM-PTP1B ${ }^{-1}$ mice that spontaneously developed tumours had a complete BMDM PTP1B-deficiency, whereas LysM-PTP1B $^{+/-}$mice displayed decreased PTP1B expression (50-80\% decrease compared to PTP1B ${ }^{\text {fl/fl }}$ controls) and did not develop tumours (Supplemental Figure 2a\&b)(n=12/genotype).

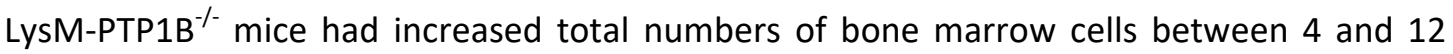
months of age (Figure $1 \mathrm{~b}$ ), but these numbers declined sharply after 12 months of age compared to that of PTP1B $\mathrm{B}^{\mathrm{fl} / \mathrm{fl}}$ mice.

\section{LysM-PTP1B ${ }^{-/-}$mice develop acute myeloid-like leukaemia phenotype}

The decline in total numbers of bone marrow cells with age could be indicative of the release of immature cells from the bone marrow; therefore the characteristics of circulating cells were assessed. LysM-PTP1B ${ }^{-/-}$mice exhibited an increase in leukocytosis (Fig 1c-e), with an increasing proportion of blast cells and $50 \%$ decrease in the percentage of neutrophils (Fig $1 \mathrm{~d}$ ) at the time of death. Most strikingly, this was accompanied by the appearance of a morphologically distinct blast cell population (Supplemental Figure $2 \mathrm{c}, \mathrm{d}$ ) in LysM-PTP1B $^{-/-}$mice, which had irregular nuclei with some folding, and a high nuclear:cytoplasm ratio with poor granulation. This population was absent in PTP1B ${ }^{\mathrm{fl} / \mathrm{fl}}$ mice (Figure 1d) and comprised $<1 \%$ of circulating white blood cells (WBC) in LysM-PTP1B $^{+/-}$mice (Supplemental Figure 2e,f).

The development of this blast cell population was time-dependent, with a 5-fold increase from 9-months to 18-months of age (Figure 1c). Further assessment of blood parameters confirmed a decrease in haematocrit, suggesting anaemia in LysM-PTP1B ${ }^{-/-}$mice (Figure 1e), along with an increase in total WBC counts (Figure 1f) in the circulation, and an increase in the percentage of reticulocytes (immature red blood cells) (Figure 1g).

Liver and lung tumours in LysM-PTP1B ${ }^{-/-}$mice all stained positively for the myeloid-specific enzyme myeloperoxidase, verifying their myeloid lineage, and thereby suggesting the development 
of tumours to be similar to previously reported myeloproliferative disorders, with mutations in PTP1B (Figure 1h)(19, 20) .

\section{Tumour development in LysM-PTP1 ${ }^{-/-}$mice is characterised by changes in monocytic-macrophage}

\section{cell populations in spleen and liver}

LysM-PTP1B $^{-/}$mice that developed a leukaemia-like blood phenotype, exhibited swollen abdomens due to splenomegaly and hepatomegaly, with visible development of extranodal tumours (Figure 2a); next, we sought to determine the nature of these tumours. Large tumours between 8 and $10 \mathrm{~mm}$ in diameter developed in multiple locations outside of the organs, including around the small intestine, limb joints and neck (Supplemental Figure 3a, b, c).

Hematoxylin and eosin (H\&E) staining of extramedullary tumours revealed clusters of densely packed cells (Figure 2b). A large number of tumour cells displayed prominent nucleoli, abnormal mitotic figures and highly positive Ki67 staining, suggesting that these cells were synthesising large amounts of protein, were in mitosis and actively proliferating $(21,22)$. Moreover, LysM-PTP1B $^{-/-}$mice exhibited a major disruption in the normal architecture of the follicular structure of the spleen compared to PTP1B ${ }^{\mathrm{fl} / \mathrm{fl}}$ mice, as determined by H\&E and F4/80 macrophage staining (Figure 2c). Flow cytometry analysis of splenocytes isolated from 4 and 12 month old mice, demonstrated that in the spleen, there was a two fold increase in markers of both dendritic cells $\left(\mathrm{F} 4 / 80^{+} \mathrm{CD} 11 \mathrm{c}^{+}\right)$and macrophages $\left(\mathrm{F} 4 / 80^{+} \mathrm{CD} 11 \mathrm{~b}^{+}\right)$at 12 months of age (Table 1$)$.

Hepatic F4/80 staining indicated an increase in a macrophage-type population in LysM$\mathrm{PTP}^{-/-}$livers, which were not contained solely within the tumour mass, but distributed throughout the organ (Figure 2d). LysM-PTP1B ${ }^{-1-}$ mice also demonstrated an increase in hepatic gene expression of the monocytic-macrophage markers, F4/80, CD11b and CD68 compared to PTP1B ${ }^{\mathrm{fl} / \mathrm{fl}}$ mice (Figures 2e-g), in agreement with hepatic F4/80 staining, suggestive of an increase in monocytic-macrophage cells with tumour development in the liver. 
To identify global hepatic gene expression changes associated with tumour development, but prior to secondary changes allied with full tumour onset, microarray analysis was performed in livers from pre-symptomatic (6-month old) mice, injected with low-dose LPS $(0.5 \mathrm{mg} / \mathrm{kg})$ for 3 hours to mimic an inflammatory environment (Figure 2h). In total, 1989 genes were significantly upregulated and 1490 genes were significantly downregulated in LysM PTP1B ${ }^{-/-}$mice. Principal component analysis and hierarchical clustering of differentially expressed genes showed a unique profile of hepatic gene expression between LysM-PTP1B ${ }^{-/-}$and PTP1B $\mathrm{B}^{\mathrm{fl} / f l}$ mice (Supplemental Figure 4a,b). Pathway analysis of differentially expressed genes determined a significant upregulation of genes involved in lipid metabolism and downregulation of genes involved in immune system processes/responses (Figure 2h; Supplemental Figure 4c,d). Many of these lipid metabolism genes were 1.5-fold upregulated and are known targets of peroxisome proliferator-activated receptor $\alpha$ (PPAR $\alpha$ ) and sterol regulatory-element-binding protein (SREBP) (Supplemental Table 4)(23). Upregulation of mTOR and amino acid sensing activators of mTOR, lamtor 4 and 5, provide a further link to these pathways since aberrant activation of the mammalian target of rapamycin complex 1 (mTORC1) is a common molecular event in cancer, by specifically activating bioenergetic and anabolic cellular processes (24). In addition, Sirt3 and Sirt5 were upregulated and both of these protein deacetylase sirtuins have been reported to positively regulate mitochondrial fatty acid oxidation (25). These results suggest a hallmark of cancer, i.e. metabolic reprogramming in the form of increased lipid metabolism is associated with tumour development in livers of LysM-PTP1B ${ }^{-/-}$mice.

\section{Myeloid PTP1B deficiency alters expression of splenic and hepatic tissue cytokines}

Given the changes in cell populations in splenic and hepatic tissue from LysM-PTP1B ${ }^{-1-}$ mice with tumours, we investigated whether the expression levels of immunosuppressive genes were altered. Interleukin-4 (IL-4), an anti-inflammatory cytokine (26), was found to be significantly upregulated in the liver of LysM-PTP1B ${ }^{-1-}$ mice as compared to PTP1B ${ }^{\mathrm{fl} / f l}$ mice (Figure 3a). The lack of an intermediate phenotype in terms of IL-4 expression in LysM-PTP1B ${ }^{+/}$is likely due to a 
combination of changes in cell population between genotypes and tissues, coupled with a decrease in $I L-6$, which has been demonstrated to enhance macrophage polarisation towards the $M 1$ end of the spectrum and attenuate arginase and IL-4 production.

Arginase I, an enzyme highly intertwined with IL-4-mediated macrophage activation, postulated to contribute towards cancers evasion of the immune system (27), was also significantly upregulated in the liver of LysM-PTP1B ${ }^{-/-}$mice (Figure 3b). Interleukin 6 (IL-6), a cytokine more associated with inflammatory responses, but also known to play a role in regulation of the tumour microenvironment (28), was significantly upregulated in the liver of LysM-PTP1B ${ }^{-/-}$mice, without significant alterations in LysM-PTP1B ${ }^{+/-}$(Figure 3c).

High circulating levels of IL-10 are associated with immunosuppression and have been shown to encourage tumour growth, by suppressing APC-mediated immune responses (29). We previously reported that LysM-PTP1B ${ }^{-/}$mice exhibited increased expression in BMDM- and serum-IL10 (9). LysM-PTP1B ${ }^{-/-}$mice also had markedly increased expression of $I L-10$ in liver (15-fold compared to PTP1B $\mathrm{B}^{\mathrm{fl} / \mathrm{fl}}$ controls) (Figure $3 \mathrm{~d}$ ).

In the spleen, there were no differences in IL4 and Arginase I expression between genotypes (Figure 3e, f), whilst IL6 was significantly upregulated in LysM-PTP1B ${ }^{--}$mice (Figure $3 \mathrm{~g}$ ) and IL-10 was upregulated 60-fold in LysM-PTP1B ${ }^{-/}$mice in comparison to the controls (Figure 3h).

As expected, LysM-PTP1B ${ }^{-/}$mice had increased levels of serum IL-10 (Figure 3i). LysM$\mathrm{PTP}^{+/-}$mice had intermediate levels of expression in spleen and liver and circulating levels of IL-10 compared to PTP1B ${ }^{\mathrm{fl} / \mathrm{fl}}$ controls (Figure 3i). Finally, both STAT3 and STAT5 expression in hepatic and splenic tissues were also increased in LysM-PTP1B ${ }^{--}$mice (Figure $3 \mathrm{j}-\mathrm{I}$, and supplemental figure $5 \mathrm{a}-\mathrm{d}$ ).

Dysregulation of cytokines in LysM-PTP1B ${ }^{-/-}$mice is accompanied by upregulation of STAT3 and STAT5 
Constitutive activation of multiple STAT family members have been determined to be major pro-oncogenic drivers (30) and tyrosine-phosphorylated STATs are major substrates for $\operatorname{PTP1B}(9,10$, 31). We have demonstrated previously that deletion of PTP1B can increase both STAT3 tyrosine phosphorylation and STAT3 expression levels in bone marrow derived macrophages (BMDM) (9) and dendritic cells (BMDC) (11) and we also demonstrate that total levels of STAT5 protein and mRNA increase in LysM-PTP1B ${ }^{-/-}$livers and spleens (Supplemental Figure 5a-f).

To determine the level of STAT3 activity through DNA binding, ChIP-seq analysis was performed in BMDM from PTP1B ${ }^{\mathrm{fl} / \mathrm{fl}}$ and LysM-PTP1B ${ }^{-/-}$mice, under basal and IL-10 stimulated conditions. There were relatively few STAT3 binding peaks in control mice of both genotypes $(<200)$, but IL-10 treatment resulted in a $>10$-fold increase in STAT3 binding in total and in regions associated with genes (Fig 4a). Motif analysis revealed the increase in STAT3 binding occurred at the canonical STAT3 binding-motif (TTCnnnGAA e.g. TTCCnGGAA) (Fig 4b) and also TTCC and GGAA halfsites (Supplemental Figure 6). STAT3 binding peaks at selected genes were visualised in the UCSC genome browser, revealed binding near STAT3 and Diap1 genes in BMDMs from all four treatment groups; binding at the Bcl6 gene specifically in IL-10 treated mice (from both genotypes) and specific binding at several known targets of STAT3 only in LysM-PTP1B ${ }^{-1-}$ mice treated with IL-10 (e.g. Stat6, KIf4, Epas1, Lims1) (Figure 4c; Supplemental Figure 6). These results strongly suggest that increased DNA binding activity of STAT3 activity in LysM-PTP1B ${ }^{-/}$BMDM, combined with increased levels of circulating IL-10 cytokine, may contribute to the development of the acute leukaemia phenotype.

\section{LysM-PTP1B ${ }^{-/-}$mice display upregulation of $B C l-2$ and $B C l-X L$}

STAT3 and STAT5 can directly regulate the gene expression levels of mitochondrial proteins that play a key role in promoting or inhibiting apoptosis (28). Splenic STAT3 was upregulated in LysM-PTP1B $^{+/-}$and further increased in LysM-PTP1B ${ }^{--}$mice (Figure 5a). B cell lymphoma 2 (Bcl-2) and $B$ cell lymphoma extra large (Bcl-XL), two strongly anti-apoptotic proteins downstream of STAT3, 
were also induced in LysM-PTP1B ${ }^{+/-}$splenic tissue compared to PTP1B ${ }^{\mathrm{fl} / \mathrm{fl}}$ and were further increased in LysM-PTP1B ${ }^{-/-}$mice (Figure 5b\&c). Oncogenic transcription factor, B cell lymphoma 6 (Bcl-6), which can be regulated by STAT5, was significantly increased in splenic tissue of LysM-PTP1B ${ }^{+/-}$mice, but was completely suppressed in LysM-PTP1B ${ }^{-1-}$ mice (Figure $5 \mathrm{~d}$ ).

In the liver, STAT3 expression was significantly upregulated in LysM-PTP1B ${ }^{-{ }^{-}}$mice only (Figure 5e). Similarly, both $B C l-2$ and $B C l-X L$ expression were upregulated in hepatic tumourburdened tissue of LysM-PTP1B ${ }^{-/-}$mice (Figure $5 f, g$ ). The expression of these proteins was unaltered in LysM-PTP1B ${ }^{+/-}$mice compared to PTP1B ${ }^{\mathrm{fl} / \mathrm{fl}}$. In addition, $B c /-6$ was increased in the hepatic tissue of LysM-PTP1B ${ }^{+/-}$mice, but completely suppressed in LysM-PTP1B ${ }^{-/-}$mice (potentially due to differing cell composition between mouse genotypes) (Figure 5h). The altered balance of these mitochondrial proteins in LysM-PTP1B ${ }^{-/}$mice would strongly promote cell survival over cell death and thus suggests a mechanism for the myeloproliferative disorder and development of tumours in these mice.

Overall our data show for the first time that myeloid PTP1B is required to inhibit the overactivation of JAK-STAT signalling and the development of myeloid leukaemia. Moreover, high expression levels of STAT3, BCl-2 and BCl-XL (with chronic loss of myeloid PTP1B) may be due to infiltration and expansion of leukemic blast cells that have infiltrated the hepatic tissue and developed into solid extramedullary masses (chloromas), rather than primary defects within the hepatic cells themselves (Figure 5i).

\section{Ruxolitinib treatment inhibits JAK/STAT signalling in LysM-PTP1B ${ }^{-/-}$BMDM and reverses the functional phenotype observed}

In order to investigate if changes in signalling and gene expression in LysM-PTP1B ${ }^{-/}$cells were driven by over activation of JAK/STAT pathway, BMDM from pre-symptomatic, 6 month-old mice were treated with $5 \mu \mathrm{M}$ ruxolitinib, a Janus Kinase (JAK1/2) inhibitor. Ruxolitinib works by binding to the active site and thereby preventing binding of JAKs to their substrates, thus decreasing 
activity of the JAK-STAT pathway. The phosphorylation status of JAK2, a reported substrate for PTP1B in vitro (32), did not change between PTP1B ${ }^{\mathrm{fl} / \mathrm{fl}}$ controls and LysM-PTP1B ${ }^{-/-}$BMDM stimulated with LPS, with or without ruxolitinib treatment (Figure 6a, b). Treatment with ruxolitinib significantly inhibited both basal and LPS-induced STAT3 phosphorylation at its activation site Y705 $(p<0.001)$, but not the S727 site (p>0.5) (Figure 6c, d, e). STAT3 Y705 was hyperphosphorylated in LysM-PTP1B ${ }^{-}$mice (Figure $6 \mathrm{c}, \mathrm{d}$ ) and is required for the dimerisation of STAT3 and subsequent shuttling to the nucleus, where it can exert its transcriptional effects. Transcriptional activity of STAT3 is via the S727 site, which was not inhibited by ruxolitinib treatment, despite being basally hyperphosphorylated in LysM-PTP1B ${ }^{-/-}$BMDM (Figure $\left.6 c, e\right)$. However, it is important to note, that without phosphorylation at Y705, STAT3 is unable to dimerise and translocate, thus, diminishing its transcriptional effects. STAT5 phosphorylation at Y694 was similar between LysM-PTP1B ${ }^{-/-}$and PTP1B $\mathrm{B}^{\mathrm{fl} / \mathrm{fl}} \mathrm{BMDM}$, both basally and in response to LPS, and was completely blocked upon ruxolitinib treatment (Figure 6c, f).

In canonical JAK-STAT signalling, activated JAK additionally leads to the induction of downstream mTOR and ERK signalling; hence, we assessed the phosphorylation status of mTOR S2448. mTOR S2448 was significantly decreased in LysM-PTP1B ${ }^{-/-}$BMDM versus PTP1B ${ }^{\mathrm{fl} / \mathrm{fl}}(\mathrm{p}<0.05)$ (Figure 6c, g), and phosphorylation was significantly blocked by ruxolitinib treatment in both genotypes $(p<0.0101)$ (Figure $6 c, g)$. The mitogen activated protein kinase, ERK2/1, is also activated following JAK phosphorylation. While PTP1B ${ }^{\mathrm{f} / \mathrm{fl}}$ BMDM treated with LPS did not respond at T202/Y204, LysM-PTP1B ${ }^{-/-}$mice display a response curve with phosphorylation peaking at 60 minutes following stimulation (Figure $6 \mathrm{c}, \mathrm{h}$ ). In both genotypes, ERK signalling is diminished with ruxolitinib treatment $(p<0.001)$ (Figure $6 c, h)$. MAPK p38 phosphorylation at T180/Y182 is increased significantly in LysM-PTP1B ${ }^{-/-}$mice compared to PTP1B ${ }^{f l / f l}(p<0.01)$ (Figure $\left.6 c, i\right)$. While ruxolitinib treatment decreased p38 signalling significantly in both genotypes $(p<0.05)$, it was not completely supressed (Figure 6c, i). 
It has been robustly demonstrated that p38 induction can be required for IL-10 production in macrophages (33), hence, we assayed culture media for TNF $\alpha$ and IL-10 production following treatment with ruxolitinib (Figure 6j,k). TNF $\alpha$ secretion was inhibited upon PTP1B deficiency in LPSstimulated BMDM and this was reversed upon ruxolitinib treatment (Figure 6j). Conversely, IL-10 production was significantly reduced by blockade of the JAK-STAT signalling pathway in LysM-PTP1BI- BMDM ( $<<0.001)$ (Figure 6k), thus, demonstrating that dysregulation of STAT3 signalling due to myeloid-PTP1B deficiency is the driving factor in the enhancement of IL-10 production in the LysMPTP1B ${ }^{-/-}$model.

It was important to determine whether inhibiting STAT3 activity could reverse and restore the functional defects observed in LysM PTP1B ${ }^{-/}$cells. We previously demonstrated that DCs in LysM-PTP1B $^{-/-}$mice have altered functionality, with a decreased ability to prime antigen specific T cell responses and increased adherence in vivo in response to LPS stimulation (11). We now demonstrate that LysM-PTP1B ${ }^{-/}$BMDM also display this phenotype, with a significant decrease in LysM-PTP1B $^{-1-}$ BMDM ability to activate B3Z reporter T cell model $(p<0.001)$ (Figure 6l). However, treatment with ruxolitinib decreases activation of $\mathrm{B} 3 \mathrm{Z} \mathrm{T}$ cells in both PTP1B $\mathrm{B}^{\mathrm{fl} / \mathrm{fl}}$ and LysM-PTP1B ${ }^{-/-}$ BMDM, indicating that suppression of the JAK-STAT pathway downregulates functions of both genotypes to equal levels (Figure 6I). In addition, DC from LysM-PTP1B ${ }^{-1-}$ mice exhibited an increase in adhesion to collagen (11). We demonstrate that this phenotype is present in LysM-PTP1B ${ }^{-/}$ BMDM and that treatment with ruxolitinib restores the phenotype of unstimulated LysM-PTP1B ${ }^{-/-}$ BMDM to that of control unstimulated PTP1B ${ }^{\mathrm{fl} / \mathrm{fl}}$ BMDMs (Figure $6 \mathrm{~m}$ ). These data demonstrate that inhibition of JAK-STAT pathway, leads to inability of BMDM to increase adhesion to collagen substrate following LPS stimulation, and suggest that changes in the functionality of LysM-PTP1B ${ }^{-/}$ BMDM are JAK/STAT-driven. 


\section{Discussion}

Our study demonstrates that long-term complete myeloid PTP1B deficiency, as achieved in LysM-PTP1B $^{-1-}$ mice, decreases their lifespan, which recapitulates the phenotype observed with global PTP1B deletion. This phenotype is not observed with neuronal, muscle, liver or adipose specific PTP1B knockout models. PTP1B has been implicated in the development of many cancers, functioning either as a tumour promotor (34) or suppressor (35) in a tissue-dependent manner. Our findings elucidate PTP1B function in myeloid cells and provide new evidence that PTP1B acts as a tumour suppressor in myeloid lineage cells. We present data that LysM-PTP1B ${ }^{-1-}$ mice exhibit greater than normal numbers of bone marrow cells when $<12$ months of age, which declines with increasing age, concurrently with an increase in blast cells in peripheral blood, normally diagnostic of an acute leukaemia.

PTP1B has been suggested to play a role in both, colony stimulating factor 1 (CSF1) (7) signalling, and fms like tyrosine kinase (FLT-3) signalling (36), which can regulate proliferation and mobilisation of myeloid cells from the bone marrow (37). Both these molecules have been reported to signal through STAT3 $(37,38)$, and thus activation of these pathways should be a focus of future studies.

Histological analysis of LysM-PTP1B ${ }^{-/-}$tissues revealed infiltration of leukemic cells into hepatic and lung tissues, with tumour development. The tumours contained cells with a high nuclear: cytoplasmic ratio, a common feature of malignant cells (39). As the cell becomes malignant, this can affect packing of the nuclear material, often giving rise to large clumped heterochromatin and hypochromatic nuclei with wrinkled nuclear membranes (39), both of which are evident in the LysM-PTP1B $^{-/-}$tumours.

LysM-PTP1B ${ }^{-1}$ mice exhibit an increase in IL-10 expression in BMDM (9). We now report that in aged mice, the increase in IL-10 expression is systemic and found both, in serum and at mRNA level in multiple tissues. With respect to inflammatory metabolic disorders, such as T2DM, heightened IL-10 production may be advantageous, since T2DM is associated with inflammation- 
mediated PTP1B upregulation in multiple tissues. However, long-term exposure has been suggested to contribute towards tumour development, by supressing natural tumour immunity (29).

LysM-PTP1B $^{-/}$myeloid cells exhibit hyperphosphorylation of STAT3 under normal homeostatic conditions (9), in both BMDM and dendritic cells, from 6 month old mice, suggesting that changes in STAT3 occur prior to development of leukaemia. STAT5 activation has been suggested to play a role in myeloproliferative neoplasms (19). Importantly, STAT5 is not hyperphophorylated basally or upon LPS stimulation in LysM-PTP1B ${ }^{-1-B M D M . ~ S T A T 3 ~ i s ~ a t ~ t h e ~ c e n t r e ~}$ of multiple signalling cascades, and both, over-expression and constitutively active STAT3, are associated with multiple cancers, due to its anti-apoptotic and proliferative effects $(28,40-43)$. Given that LysM-PTP1B ${ }^{+/-}$mice exhibit an increase in STAT3 mRNA and protein levels in the spleen and liver without the development of tumours, it is likely that that even some PTP1B mediated STAT3 de-phosphorylation in the LysM-PTP1B ${ }^{-/+}$mice is enough to confer protection. Furthermore, we demonstrate that STAT3 inhibition in BMDM from pre-symptomatic LysM-PTP1B ${ }^{-{ }^{-}}$mice, that exhibit hyperphosphorylation of STAT3 Y705, is blocked with Ruxolitinib treatment. This blockade of STAT3 phosphorylation supresses enhanced IL-10 secretion and restores the functional phenotype of LysM-PTP1B ${ }^{-1-}$ BMDM.

STAT3 exerts many of its pro-survival and proliferative effects via downstream effects in the $\mathrm{B}$ cell lymphoma family of proteins, including changing $\mathrm{Bcl}-6$ and $\mathrm{Bcl}-2 / \mathrm{Bcl}-\mathrm{XL}$ (pro and anti-apoptotic respectively) ratios, which can alter the survival of a cell (31). The ratio of $\mathrm{Bcl}-6$ to $\mathrm{Bcl}-2 / \mathrm{Bcl}-\mathrm{XL}$ can be used as a prognostic marker for cancers and is correlated with poor survival (44). We demonstrate that this ratio is skewed in favour of the anti-apoptotic Bcl-2 and $\mathrm{Bcl}-\mathrm{XL}$ in LysM-PTP1B ${ }^{-/-}$mice, thus favouring cell survival. It has been established that enhanced survival due to increased Bcl-2 (45) is STAT3 dependent, and high levels of Bcl-2 can confer resistance to chemotherapy in myeloid leukaemias. $\mathrm{Bcl}-\mathrm{XL}$ also protects cells against a number of cytotoxic insults, including induction of cytokine resistance (46), and promotes cell survival (47), and again high expression can confer a multidrug resistant phenotype (48). It has been suggested that this is due to $\mathrm{Bcl}-\mathrm{XL}$ mediated 
inhibition of $\mathrm{p} 53$. Importantly, studies have revealed that $\mathrm{Bcl}-6^{-/-}$macrophages display a hyperproliferative phenotype, and demonstrate spontaneous IL-6 production, which may, in part, explain the high levels of IL-6 seen in LysM-PTP1B ${ }^{-/-}$mice (49). Our data demonstrate a direct imbalance, with the pro-survival $\mathrm{Bcl}-2$ and $\mathrm{Bcl}-\mathrm{XL}$ increased and their partner $\mathrm{Bcl}-6$ suppressed, tilting the balance towards survival and proliferation. It is also important to note that PTP1B deletion in haematopoetic compartments in mice, using Mx1-Cre promoter, also results in enlargement of spleen size and induction of extramedullary haematopoiesis, resulting in expansion of myeloid lineage cells and increased phosphorylation of STAT5, Akt and ERK in bone marrow. This contributed towards the development of a myeloproliferative neoplasm /myelofibrosis-like phenotype in these mice although no tumours were observed presumably because of the younger age studied (19). This further contributes to the body of evidence demonstrating the importance of PTP1B regulation of the JAK/STAT pathway and importance of this enzyme as a tumour suppressor.

We propose that complete deficiency of PTP1B in myeloid cells results in the development of leukaemia through multiple mechanisms (Figure 5i). An increase in bone marrow cellularity in young mice, coupled with increased survival and proliferation due to STAT3 mediated effects (potentially involving FLT3), increases the chance of secondary mutations. Meanwhile, the development of a systemic immunosuppressive environment through high IL-10 levels and inability of antigen presenting cells to prime immune responses may lead to a lack of immune surveillance. This would be further exacerbated through the IL-10-STAT3 signalling axis, thus establishing a positive feedback loop to further drive unregulated proliferation and survival through imbalance of Bcl-6 and Bcl-2/Bcl-XL. In summary, our data demonstrate a tumour suppressive role for myeloid PTP1B and provide further evidence that PTP1B is a critical gene in the pathogenesis of del(20q) myeloid malignancies (19).

Acknowledgements: The authors thank the University of Aberdeen Histology and Microscopy core facility, as well as the National Health Services (NHS) Grampian Pathology services for processing of 
Author Manuscript Published OnlineFirst on November 9, 2017; DOI: 10.1158/0008-5472.CAN-17-0946

Author manuscripts have been peer reviewed and accepted for publication but have not yet been edited.

histology slides. The authors also thank the Centre for Genome Enabled Biology and Medicine at the University of Aberdeen where microarray and ChIP sequencing experiments were processed. Flow cytometry analyses were performed at the University of Aberdeen Ian Fraser Flow Cytometry Centre. 
Author Manuscript Published OnlineFirst on November 9, 2017; DOI: 10.1158/0008-5472.CAN-17-0946

Author manuscripts have been peer reviewed and accepted for publication but have not yet been edited.

\section{References}

1. Elchebly M, Payette P, Michaliszyn E, Cromlish W, Collins S, Loy AL, et al. Increased Insulin Sensitivity and Obesity Resistance in Mice Lacking the Protein Tyrosine Phosphatase-1B Gene. Science. 1999 03/05;283(5407):1544.

2. Klaman LD, Boss O, Peroni OD, Kim JK, Martino JL, Zabolotny JM, et al. Increased Energy Expenditure, Decreased Adiposity, and Tissue-Specific Insulin Sensitivity in Protein-Tyrosine Phosphatase 1B-Deficient Mice. Mol Cell Biol. 2000 04/24;20(15):5479-89.

3. Agouni A, Mody N, Owen C, Czopek A, Zimmer D, Bentires-Alj M, et al. Liver-Specific Deletion of Protein Tyrosine Phosphatase (PTP) 1B Improves Obesity- and Pharmacologically-Induced Endoplasmic Reticulum Stress. Biochem J. 2011 09/01;438(2):369-78.

4. Delibegovic M, Bence KK, Mody N, Hong E, Ko HJ, Kim JK, et al. Improved Glucose Homeostasis in Mice with Muscle-Specific Deletion of Protein-Tyrosine Phosphatase 1B. Mol Cell Biol. 2007 08/13;27(21):7727-34.

5. Owen C, Czopek A, Agouni A, Grant L, Judson R, Lees EK, et al. Adipocyte-Specific Protein Tyrosine Phosphatase 1B Deletion Increases Lipogenesis, Adipocyte Cell Size and Is a Minor Regulator of Glucose Homeostasis. PLoS ONE. 2012 01/30;7(2):e32700.

6. Balavenkatraman KK, Aceto N, Britschgi A, Mueller U, Bence KK, Neel BG, et al. Epithelial ProteinTyrosine Phosphatase 1B (PTP1B) Contributes to the Induction of Mammary Tumors by HER2/Neu but is not Essential for Tumor Maintenance. MCR. 2011 08/17;9(10):1377-84.

7. Heinonen KM, Dubé N, Bourdeau A, Lapp WS, Tremblay ML. Protein tyrosine phosphatase 1B negatively regulates macrophage development through CSF-1 signaling. Proc Natl Acad Sci U SA. 2006 February 21;103(8):2776-81.

8. Traves PG, Pardo V, Pimentel-Santillana M, Gonzalez-Rodriguez A, Mojena M, Rico D, et al. Pivotal role of protein tyrosine phosphatase $1 \mathrm{~B}$ (PTP1B) in the macrophage response to pro-inflammatory and anti-inflammatory challenge. Cell Death Dis. 2014 03/13;5:e1125.

9. Grant L, Shearer KD, Czopek A, Lees EK, Owen C, Agouni A, et al. Myeloid-Cell Protein Tyrosine Phosphatase-1B Deficiency in Mice Protects Against High-Fat Diet and Lipopolysaccharide-Induced Inflammation, Hyperinsulinemia, and Endotoxemia Through an IL-10 STAT3-Dependent Mechanism. Diabetes. 2014 01/23;63(2):456.

10. Pike KA, Hutchins AP, Vinette V, Théberge J, Sabbagh L, Tremblay ML, et al. Protein Tyrosine Phosphatase 1B Is a Regulator of the Interleukin-10-Induced Transcriptional Program in Macrophages. Sci Signal. 2014 05/06;7(324):ra43.

11. Martin-Granados C, Prescott AR, Le Sommer S, Klaska IP, Yu T3, Muckersie E, Giuraniuc CV, Grant $\mathrm{L}$, Delibegovic M, Forrester JV. A key role for PTP1B in dendritic cell maturation, migration, and T cell activation. J Mol Cell Biol. 2015;0(0):1.

12. Soysal S, Obermann EC, Gao F, Oertli D, Gillanders WE, Viehl CT, et al. PTP1B expression is an independent positive prognostic factor in human breast cancer. Breast Cancer Res Treat. 2012 12/16;137(2):10.1007/s10549,012-2373-1. 
Author Manuscript Published OnlineFirst on November 9, 2017; DOI: 10.1158/0008-5472.CAN-17-0946

Author manuscripts have been peer reviewed and accepted for publication but have not yet been edited.

13. Lessard L, Labbé D,P., Deblois G, Bégin L,R., Hardy S, Mes-Masson A, et al. PTP1B is an androgen receptor-regulated phosphatase associated with tumor-promoting functions in prostate cancer. Cancer Res. 2012 01/26;72(6):1529-37.

14. Yu H, Lee H, Herrmann A, Buettner R, Jove R. Revisiting STAT3 signalling in cancer: new and unexpected biological functions. Nat Rev Cancer. 2014 print;14(11):736-46.

15. Bence KK, Delibegovic M, Xue B, Gorgun CZ, Hotamisligil GS, Neel BG, et al. Neuronal PTP1B regulates body weight, adiposity and leptin action. Nat Med. 2006 print;12(8):917-24.

16. Clausen BE, Burkhardt C, Reith W, Renkawitz R, Förster I. Conditional gene targeting in macrophages and granulocytes using LysMcre mice. Transgenic Res. 1999;8(4):265-77.

17. Spurrell DR, Luckashenak NA, Minney DC, Chaplin A, Penninger JM, Liwski RS, et al. Vav1 Regulates the Migration and Adhesion of Dendritic Cells. J Immunol. 2009 06/19;183(1):310.

18. Karttunen J, Shastri N. Measurement of ligand-induced activation in single viable T cells using the lacZ reporter gene. Proc Natl Acad Sci U S A. 1991 05/01;88(9):3972-6.

19. Jobe F, Patel B, Kuzmanovic T, Makishima H, Yang Y, Przychodzen B, et al. Deletion of Ptpn1 induces myeloproliferative neoplasm. Leukemia. 2017 print;31(5):1229-34.

20. Mei W, Wang K, Huang J, Zheng X. Cell Transformation by PTP1B Truncated Mutants Found in Human Colon and Thyroid Tumors. PLoS ONE. 2016 11/17;11(11):e0166538.

21. Derenzini M, Treré D, Pession A, Montanaro L, Sirri V, Ochs RL. Nucleolar function and size in cancer cells. Am J Pathology. 1998 05;152(5):1291-7.

22. Scholzen T, Gerdes J. The Ki-67 protein: From the known and the unknown. J Cell Physiol. 2000;182(3):311-22.

23. Kersten S. Integrated physiology and systems biology of PPAR $\alpha$. Mol Metab. 2014 July 2014;3(4):354-71.

24. Düvel K, Yecies JL, Menon S, Raman P, Lipovsky Al, Souza AL, et al. Activation of a metabolic gene regulatory network downstream of mTOR complex 1. Mol Cell. 2010 07/30;39(2):171-83.

25. Rardin MJ, He W, Nishida Y, Newman JC, Carrico C, Danielson SR, et al. SIRT5 regulates the mitochondrial lysine succinylome and metabolic networks. Cell metabolism. 2013 12/03;18(6):92033.

26. Hosoyama T, Aslam MI, Abraham J, Prajapati SI, Nishijo K, Michalek JE, et al. IL-4R Drives Dedifferentiation, Mitogenesis and Metastasis in Rhabdomyosarcoma. Clin. Cancer Res. 2011 05/01;17(9):2757-66.

27. Rodriguez PC, Quiceno DG, Zabaleta J, Ortiz B, Zea AH, Piazuelo MB, et al. Arginase I Production in the Tumor Microenvironment by Mature Myeloid Cells Inhibits T-Cell Receptor Expression and Antigen-Specific T-Cell Responses. Clin. Cancer Res. 2004;64(16):5839-49.

28. Bromberg J, Wang TC. Inflammation and Cancer: IL-6 and STAT3 Complete the Link. Cancer Cell. 2009 2/3;15(2):79-80. 
Author Manuscript Published OnlineFirst on November 9, 2017; DOI: 10.1158/0008-5472.CAN-17-0946

Author manuscripts have been peer reviewed and accepted for publication but have not yet been edited.

29. Sharma S, Stolina M, Lin Y, Gardner B, Miller PW, Kronenberg M, et al. T Cell-Derived IL-10 Promotes Lung Cancer Growth by Suppressing Both T Cell and APC Function. J Immunol.

1999;163(9):5020-8.

30. Yu H, Pardoll D, Jove R. STATs in cancer inflammation and immunity: a leading role for STAT3. Nat Rev Cancer. 2009 print;9(11):798-809.

31. Zhang X, Guo A, Yu J, Possemato A, Chen Y, Zheng W, et al. Identification of STAT3 as a substrate of receptor protein tyrosine phosphatase T. Proc Natl Acad Sci U S A. 2006 11/15;104(10):4060-4.

32. Michael P. Myers, Jannik N. Andersen, Alan Cheng, Michel L. Tremblay, Curt M. Horvath $¥$, JeanPatrick Parisien, Annette Salmeen, David Barford and Nicholas K. Tonks. TYK2 and JAK2 Are Substrates of Protein-tyrosine Phosphatase 1B. J Biol Chem. 2001;276:47771.

33. Symons A, Beinke S, Ley SC. MAP kinase kinase kinases and innate immunity. Trends Immunol. 2006;27(1):40-8.

34. Wiener J, Kernsm B, Harvey E, Conaway M, Iglehart J, Berchuck A, et al. Overexpression of the protein tyrosine phosphatase PTP1B in human breast cancer: association with p185c-erbB-2 protein expression. J Natl Cancer Inst. 1994;86:372-8.

35. Labbé DP, Uetani N, Vinette V, Lessard L, Aubry I, Migon E, et al. PTP1B Deficiency Enables the Ability of a High-Fat Diet to Drive the Invasive Character of PTEN-Deficient Prostate Cancers. Cancer Res. 2016;76(11):3130-5.

36. Schmidt-Arras D, Böhmer S, Koch S, Müller JP, Blei L, Cornils H, et al. Anchoring of FLT3 in the endoplasmic reticulum alters signaling quality. Blood. 2009;113(15):3568-76.

37. Fukuda S, Broxmeyer HE, Pelus LM. Flt3 ligand and the Flt3 receptor regulate hematopoietic cell migration by modulating the SDF-1 $\alpha$ (CXCL12)/CXCR4 axis. Blood. 2005;105(8):3117-26.

38. Novak U, Harpur A, Paradiso L, Kanagasundaram V, Jaworowski A, Wilks A, et al. Colonystimulating factor 1-induced STAT1 and STAT3 activation is accompanied by phosphorylation of Tyk2 in macrophages and Tyk2 and JAK1 in fibroblasts. Blood. 1995;86(8):2948-56.

39. Zink D, Fischer AH, Nickerson JA. Nuclear structure in cancer cells. Nat Rev Cancer. 2004 print;4(9):677-87.

40. Bhattacharya S, Ray R, Johnson L. STAT3-mediated transcription of Bcl-2, Mcl-1 and c-IAP2 prevents apoptosis in polyamine-depleted cells. Biochem J. 2005 07/28;392:335-44.

41. Catlett-Falcone R, Landowski TH, Oshiro MM, Turkson J, Levitzki A, Savino R, et al. Constitutive Activation of Stat3 Signaling Confers Resistance to Apoptosis in Human U266 Myeloma Cells. Immunity. 1999 1/1;10(1):105-15.

42. Kujawski M, Kortylewski M, Lee H, Herrmann A, Kay H, Yu H. Stat3 mediates myeloid cell dependent tumor angiogenesis in mice. J Clin Invest. 2008 07/23;118(10):3367-77.

43. Shain KH, Yarde DN, Meads MB, Huang M, Jove R, Hazlehurst LA, et al. $\beta 1$ Integrin Adhesion Enhances IL-6-Mediated STAT3 Signaling in Myeloma Cells: Implications for Microenvironment Influence on Tumor Survival and Proliferation. Cancer Res. 2009;69(3):1009-15. 
Author Manuscript Published OnlineFirst on November 9, 2017; DOI: 10.1158/0008-5472.CAN-17-0946

Author manuscripts have been peer reviewed and accepted for publication but have not yet been edited.

44. Campos L, Rouault J, Sabido O, Oriol P, Roubi N, Vasselon C, et al. High expression of bcl-2 protein in acute myeloid leukemia cells is associated with poor response to chemotherapy. Blood. 1993;81(11):3091-6.

45. Sujoy Bhattacharya, Ramesh M. Ray, Leonard R. Johnson. STAT3-mediated transcription of Bcl-2, Mcl-1 and C-IAP2 prevents apoptosis in polyamine-depleted cells . Biochem J. 2005;392:335-44.

46. Huang DC, Cory S, Strasser A. Bcl-2, Bcl-xL and adenovirus protein E1B19kD are functionally equivalent in their ability to inhibit cell death. Oncogene. 1997;14:405-14.

47. Motoyama N, Wang F, Roth K, Sawa H, Nakayama K, Nakayama K, et al. Massive cell death of immature hematopoietic cells and neurons in Bcl-x-deficient mice. Science. 1995;267(5203):1506-10.

48. Minn A, Rudin C, Boise L, Thompson C. Expression of bcl-xL can confer a multidrug resistance phenotype. Blood. 1995;86(5):1903-10.

49. Yu RY, Wang X, Pixley FJ, Yu JJ, Dent AL, Broxmeyer HE, et al. BCL-6 negatively regulates macrophage proliferation by suppressing autocrine IL-6 production. Blood. 2005 02/02;105(4):1777. 


\begin{tabular}{|c|c|c|c|c|c|c|}
\hline \multirow[t]{2}{*}{ Marker(s) } & \multicolumn{3}{|c|}{4 months } & \multicolumn{3}{|c|}{12 months } \\
\hline & PTP1B ${ }^{f / f l}$ & $\begin{array}{l}\text { LysM- } \\
\text { PTP1B/- }\end{array}$ & $\begin{array}{c}\text { Significance } \\
\text { Level }\end{array}$ & PTP1B ${ }^{f / / f l}$ & $\begin{array}{l}\text { LysM- } \\
\text { PTP1B } /-\end{array}$ & $\begin{array}{c}\text { Significance } \\
\text { Level }\end{array}$ \\
\hline CD3+ & $\begin{array}{c}35.37 \pm \\
6.67\end{array}$ & $\begin{array}{c}37.72 \pm \\
0.87\end{array}$ & ns & $\begin{array}{c}31.03 \pm \\
0.56\end{array}$ & $\begin{array}{c}30.88 \pm \\
1.64\end{array}$ & ns \\
\hline CD4+ & $\begin{array}{c}18.35 \pm \\
3.66\end{array}$ & $\begin{array}{c}19.87 \pm \\
1.37\end{array}$ & ns & $\begin{array}{c}16.93 \pm \\
0.54\end{array}$ & $\begin{array}{c}15.48 \pm \\
3.87\end{array}$ & ns \\
\hline $\begin{array}{l}\text { CD4+ } \\
\text { CD25+ }\end{array}$ & $\begin{array}{c}0.72 \pm \\
0.13\end{array}$ & $\begin{array}{c}0.84 \pm \\
0.07\end{array}$ & ns & $\begin{array}{c}1.01 \pm \\
0.13\end{array}$ & $\begin{array}{c}1.37 \pm \\
0.16\end{array}$ & $\mathrm{P}<0.01(* *)$ \\
\hline CD8+ & $\begin{array}{c}10.15 \pm \\
4.77\end{array}$ & $\begin{array}{c}10.47 \pm \\
0.79\end{array}$ & ns & $\begin{array}{c}10.82 \pm \\
1.42\end{array}$ & $\begin{array}{c}8.50 \pm \\
1.03\end{array}$ & $P<0.5\left(^{*}\right)$ \\
\hline $\begin{array}{l}\text { CD8+ } \\
\text { CD25+ }\end{array}$ & $\begin{array}{c}0.23 \pm \\
0.02\end{array}$ & $\begin{array}{l}0.34 \pm \\
0.05\end{array}$ & ns & $\begin{array}{c}0.23 \pm \\
0.05\end{array}$ & $\begin{array}{c}0.41 \pm \\
0.11\end{array}$ & $P<0.5\left(^{*}\right)$ \\
\hline B220+ & $\begin{array}{c}66.35 \pm \\
7.86\end{array}$ & $\begin{array}{c}63.32 \pm \\
0.85\end{array}$ & ns & $\begin{array}{c}68.20 \pm \\
1.32\end{array}$ & $\begin{array}{c}57.28 \pm \\
9.80\end{array}$ & ns \\
\hline $\begin{array}{l}\text { CD11c+ } \\
\text { F4/80+ }\end{array}$ & $\begin{array}{c}3.33 \pm \\
1.08\end{array}$ & $\begin{array}{c}2.67 \pm \\
0.50\end{array}$ & ns & $\begin{array}{c}2.48 \pm \\
0.28\end{array}$ & $\begin{array}{c}6.39 \pm \\
2.16\end{array}$ & $\mathrm{P}<0.01(* *)$ \\
\hline $\begin{array}{l}\text { CD11b+ } \\
\text { F4/80+ }\end{array}$ & $\begin{array}{c}8.53 \pm \\
2.28\end{array}$ & $\begin{array}{c}7.24 \pm \\
0.70\end{array}$ & ns & $\begin{array}{c}5.67 \pm \\
0.50\end{array}$ & $\begin{array}{c}15.12 \pm \\
3.44\end{array}$ & $\begin{array}{c}\mathrm{P}<0.001 \\
(* * *)\end{array}$ \\
\hline
\end{tabular}

Table 1: Cellular composition of PTP1B ${ }^{\mathrm{fl} / \mathrm{fl}}$ and LysM-PTP1B ${ }^{-/-}$mouse spleens at 4 and 12 months of age. Flow cytometry analysis of the cellular composition of mouse spleens at 4 and 12 months old demonstrate significant increase in the CD4 T cell compartment of the spleen in 12 month old LysMPTP1B $^{-1-}$ mice $(p<0.01)$ and CD8 T cell compartment $(p<0.5)$. Analysis revealed that the myeloid population is significantly increased in LysM-PTP1B ${ }^{-/-}$mice, with a 2 fold increase in both, $\mathrm{F} 4 / 80^{+}$

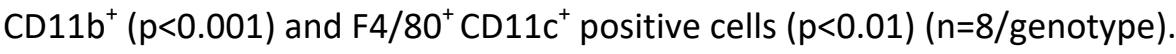




\section{Figure Legends:}

Figure 1: Myeloid specific PTP1B deletion leads to decreased lifespan and development of acute myeloid leukaemia. (a) Survival curve of LysM-PTP1B ${ }^{-/-}$mice (white diamonds,) LysM-PTP1B ${ }^{+/-}$mice (grey diamonds) and PTP1B ${ }^{\mathrm{fl} / \mathrm{fl}}$ control mice (black diamonds) in weeks ( $\mathrm{n}=12 /$ genotype). LysMPTP1B-/- mice have a significantly shortened lifespan in comparison to LysM-PTP1B+/- and PTP1B $\mathrm{B}^{\mathrm{fl} / \mathrm{fl}}$ control mice $(\mathrm{p}<0.001)$. (b) Number of bone marrow cells harvested from LysM-PTP1B ${ }^{-/-}$mice (grey) and PTP1B $\mathrm{B}^{\mathrm{fl} / \mathrm{fl}}$ mice (black) over time in weeks $(\mathrm{p}<0.001$, at all time points) $(\mathrm{n}=4 /$ time point). (c) Percentage of blast cells in peripheral blood over time in weeks relative to total white blood cells $(p<0.001)$ ( $n=12 /$ genotype). (d) Differential blood counts from PTP1B ${ }^{+/+}$and LysM-PTP1B ${ }^{-/}$mice at time of death, cell subsets are expressed as percentage of white blood cells, neutrophils were significantly decreased in LysM-PTP1B ${ }^{-/-}$mice $(p<0.05)$ and there was a significant increase in blast cell population in LysM-PTP1B ${ }^{-/-}$mice in comparison to $\mathrm{PTP}_{1 \mathrm{~B}^{+/+}}$mice $(\mathrm{p}<0.001)(\mathrm{n}=12 /$ genotype). (e) Haematocrits of PTP1B $\mathrm{B}^{\mathrm{fl} / \mathrm{fl}}$ mice (black) were reduced in comparison to LysM-PTP1B ${ }^{-/-}$mice (grey) $(p<0.001)\left(n=8 /\right.$ genotype). (f) Total white blood cell counts are increased in PTP1B $B^{f / f l}$ mice (black) in comparison to LysM-PTP1B ${ }^{-/-}$(grey) mice $(p<0.01$ ) from $10 \mathrm{ul}$ of whole blood ( $n=8 /$ group). (g) Percentage of immature red blood cells (reticulocytes) relative to total red blood cell count, LysM$\mathrm{PTP}^{-1-}$ mice have an increase in reticulocytosis $(p<0.001)$ representative image of blood slide is also shown with black arrows indicating reticulocytes. (h) Representative (40X magnification) Myeloperoxidase IHC staining of tumour burdened liver and lung tissue.

Figure 2: LysM-PTP1B ${ }^{-/}$phenotype is characterised by tumour formation in multiple tissues and severe disruption to splenic architecture. (a) Spleen to body weight ratio at 72 weeks (18 months) is significantly increased in LysM-PTP1B ${ }^{-/-}$mice (grey) when compared to of PTP1B $\mathrm{B}^{\mathrm{fl} / \mathrm{fl}}$ mice (black) control mice $(p<0.0001)\left(n=6 /\right.$ genotype). Representative post mortem photograph of LysM-PTP1B ${ }^{-/-}$ mouse with splenomegaly is shown. (b) Histological analysis of tumour burdened tissues using 
haemotoxylin and eosin (H\&E) staining. Representative slides from LysM-PTP1B ${ }^{-{ }^{-}}$liver, lungs, and solid tumours are shown ( $n=12 /$ genotype) at $40 x$ magnification. (c) Histology from PTP1B ${ }^{\mathrm{fl} / \mathrm{f}}$ and LysM-PTP1B $^{-/}$mice, representative images from both genotypes is displayed at $40 \mathrm{x}$ magnification. From top to bottom: H\&E ( $n=12 /$ genotype), F4/80 ( $n=6 /$ genotype) and Ki67 ( $n=6 /$ genotype). (d) Representative liver F4/80 IHC staining at 40x magnification is shown, from left to right; PTP1B $\mathrm{B}^{\mathrm{fl} / \mathrm{fl}}$ control mice, LysM-PTP1B ${ }^{+/-}$and LysM-PTP1B ${ }^{-/-}$(n=6/genotype). Gene expression was investigated using 9PCR, (e) $f 4 / 80$ (f) $c d 11 b$ (g) $c d 68$ in liver tissue of PTP1B ${ }^{\mathrm{fl} / f 1}$ (black), LysM-PTP1B ${ }^{+/-}$(grey) and LysM-PTP1B ${ }^{-1-}$ (white) mice ( $n=12 /$ genotype) ( $p$ values $\left.-p^{*}<0.05 .{ }^{* *} p<0.01,{ }^{* * *} p<0.001\right)$. (h) Top gene ontology terms for genes (involved in biological processes) significantly upregulated or downregulated from hepatic gene expression microarray of Ptp1b fl/fl mice $(\mathrm{n}=5)$ or LysM-Ptp1b-/mice $(n=4)$, aged 6 months, injected with LPS for 3 hours.

Figure 3: Dysregulation of cytokines in LysM-PTP1B ${ }^{-1-}$ mice is accompanied by changes in STAT3 expression. Gene expression was assessed by qPCR in the liver: (a) il-4 (b) arginase (c) il-6 and (d) il10, and spleen: (e) il-4 (f) arginase (g) il-6 and (h) il-10 of PTP1B ${ }^{\mathrm{fl} / \mathrm{fl}}$ (black), LysM-PTP1B ${ }^{+-}$(grey) and LysM-PTP1B ${ }^{--}$(white) mice ( $n=12 /$ genotype). (i) Plasma IL-10 levels were investigated by ELISA, showing a significantly increased plasma IL-10 in LysM-PTP1B ${ }^{-/-}$mice $(p<0.001)$ and LysM-PTP1B ${ }^{+/-}$ $(p<0.05)$ in comparison to PTP1B $B^{f / f l}$ control mice ( $n=12 /$ genotype). (j) Protein levels of STAT3 in liver and spleen tissues, as analysed by immunoblotting; representative STAT3 blot is shown using GAPDH loading control ( $\mathrm{n}=10 /$ genotype). (K) Quantification of STAT3 in liver and (I) spleen relative to GAPDH ( $n=10 /$ genotype) ( $p$ values $\left.-p^{*}<0.05 .{ }^{* *} p<0.01,{ }^{* * *} p<0.001\right)$.

Figure 4. STAT3 ChIP-seq in BMDM from Ptp1b ${ }^{\mathrm{fl} / \mathrm{fl}}$ and LysM-Ptp1b ${ }^{-/-}$mice

(a) Number of STAT3 peaks (clear) and associated genes (black bars) as determined by ChIP-seq in BMDM treated with IL10 (4 hours) from Ptp1b fl/fl and LysM-Ptp1b-/- mice ( $\mathrm{n}=4$ mice per group). 
(b): Occurrences of known classic STAT3 motifs in ChIP peaks from each group. (c): STAT3 binding peaks at selected genes were visualised in the UCSC genome browser. Chromosomal locations are shown at the top of each panel and gene positions are indicated at the bottom. Abbreviations:

Diap1, Death-associated inhibitor of apoptosis 1; Bcl6, B-cell lymphoma-6; KIf4, Kruppel-like factor 4; Epas1, endothelial PAS domain protein 1, also known as HIF-2 $\alpha$; Lims1, LIM and senescent cell antigen-like domains 1, also known as PINCH.

Figure 5: LysM-PTP1B-/- mice have increased expression of the Bcl-2 family anti-apoptotic proteins Bcl-2 and Bcl-XL. Gene expression analysis of spleen (a) stat3 (b) $b c l-2$ (c) $b c l-x l$ (d) $b c l-6$ and liver (e) stat3 (f) bcl-2 (g) bcl-xland (h) bcl-6. ( $\mathrm{n}=12$ /genotype) (p values $\left.-\mathrm{p}^{*}<0.05 .{ }^{* *} \mathrm{p}<0.01,{ }^{* * *} \mathrm{p}<0.001\right)$. (i) Proposed model for the role of PTP1B in the development of leukaemia. Deletion of PTP1B in myeloid cells results in increased proliferation and survival in the bone marrow possibly via CSF-1 STAT3 signalling axis leading to increase in bone marrow cells. Immature blast cells in the bone marrow are released prematurely into the circulation where they proliferate and seed into tissues such as the liver and lung to disrupt normal homeostasis. Infiltration and expansion is accompanied by changes in JAK-STAT signalling and changes in tissue cytokine profile, leading to establishment of a tumour microenvironment within the tissue.

\section{Figure 6 Treating LysM PTP1B ${ }^{-/-}$BMDM with Ruxolitinib restores phenotype}

(a) Representative blots from immunoprecipitation of $\mathrm{p}$-Tyr, and immunoblotting for JAK2 in PTP1B $^{\mathrm{fl} / \mathrm{fl}}$ and LysM PTP1B ${ }^{-/-}$BMDM. (b) Quantification of $\mathrm{p}$-Tyr JAK2 IP immunoblots relative to GAPDH input control ( $n=3$ /genotype; mean \pm SEM). (c) Immunoblots for pSTAT3 Y705, pSTAT3 S727, STAT3, pSTAT5 Y694, STAT5, p-mTOR S2448, mTOR, pERK1/2 T202/T204, ERK, GAPDH, p-p38 T180/T182, and p38. Quantification by rolling densitometry scanning of (d) pSTAT3 Y705, (e) pSTAT3 S727, (f) pSTAT5 Y694, (g) p-mTOR S2448, (h) pERK1/2 T202/Y204, (i) p-p38 T180/Y182 
( $n=3 /$ genotype for all targets; mean \pm SEM). (j) TNF $\alpha$ ELISA and (k) IL-10 ELISA of culture media from Ruxolitinib treated PTP1B ${ }^{f / f l}$ and LysM PTP1B ${ }^{-/-}$BMDM ( $n=3$ / genotype in duplicate; mean \pm SEM). (I) $\beta$-galactosidase assay with B3Z cells shows that LysM PTP1B ${ }^{-/}$BMDM are not able to activate a T reporter cell line to the same extent as control BMDM; this is reversed by Ruxolitinib treatment $(n=3$ in triplicates; mean \pm SEM), (m) LysM PTP1B ${ }^{-/-}$BMDM are more adhesive to collagen substrate than $\mathrm{PTP1B}^{\mathrm{fl} / \mathrm{fl} \mathrm{BMDM}}$ at basal level and following LPS treatment; this is reversed by Ruxolitinib treatment (100ng/ml, 24 hours)(n=3/genotype; mean \pm SEM) (Significance; * $=p<0.05, * * p<0.01$, $\mathrm{p}<0.001)$ 


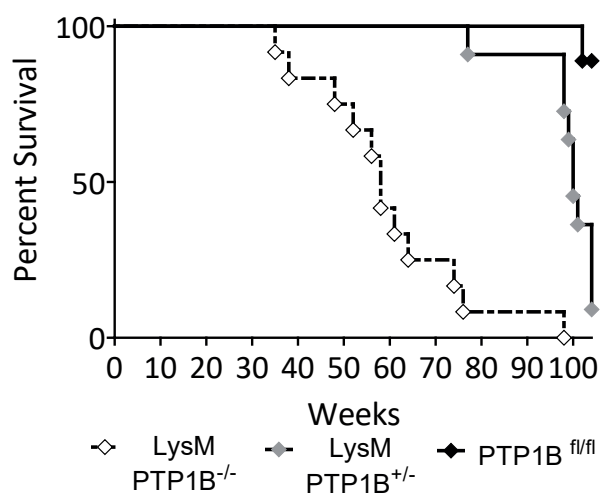

d

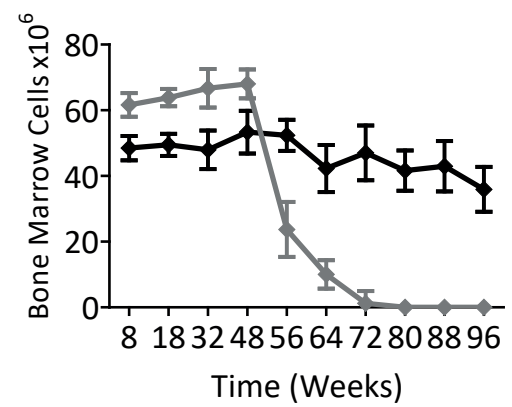

$\leftarrow$ LysM PTP1B ${ }^{-1-} \leftarrow$ PTP1B ${ }^{f / f l}$

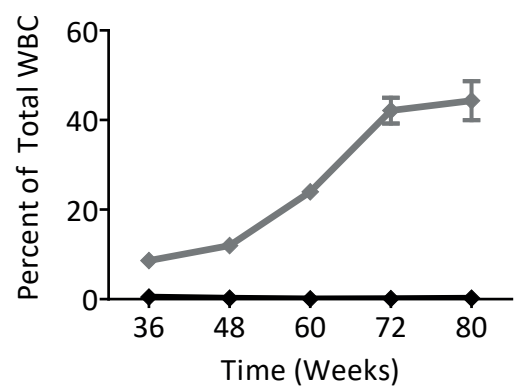

$\approx$ LysM PTP1B ${ }^{-1-}$ $\leftarrow$ PTP1B ${ }^{\text {fl/fi }}$ e

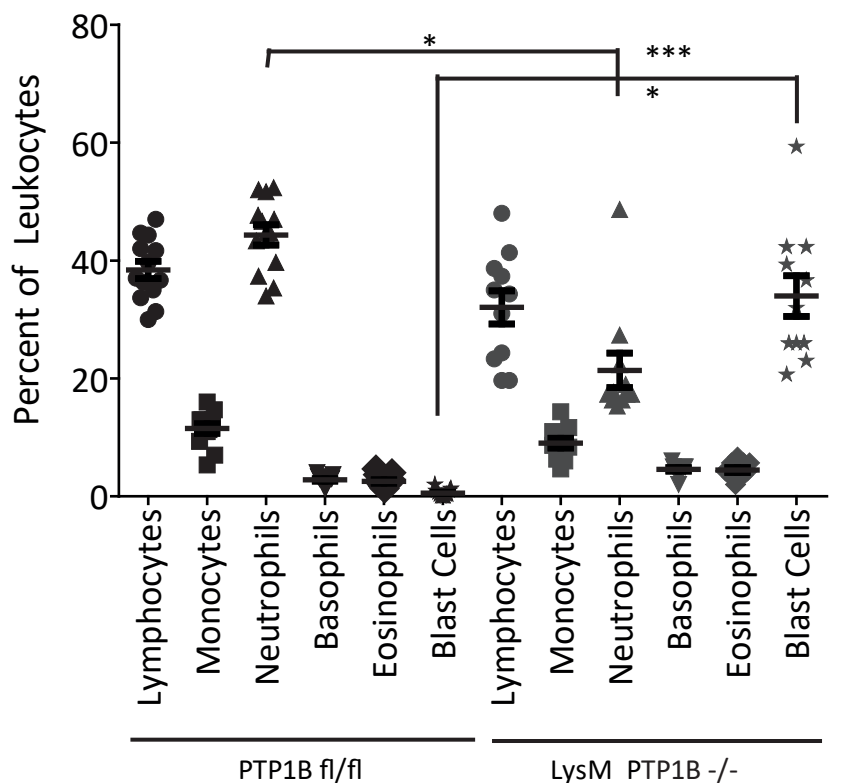

g

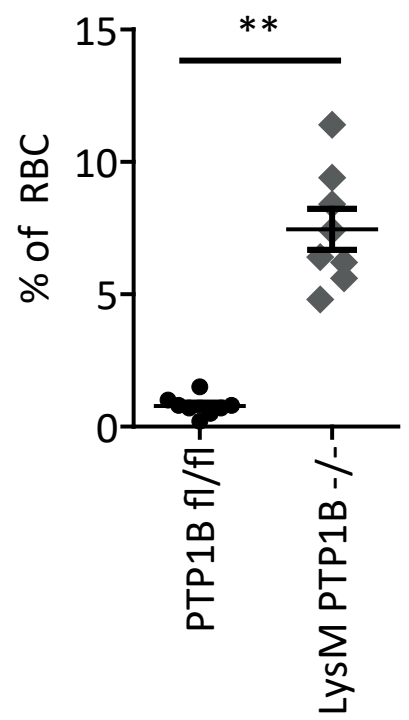

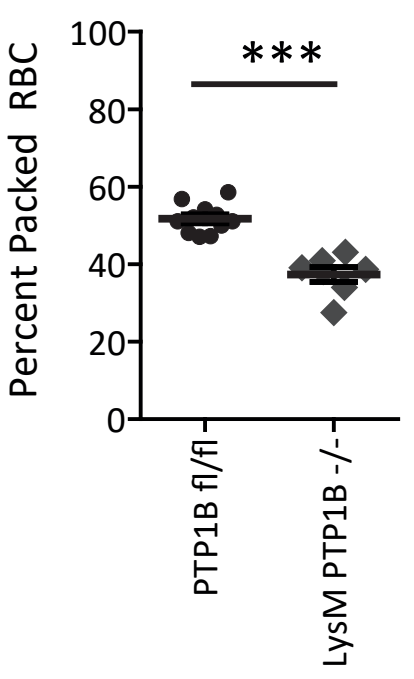

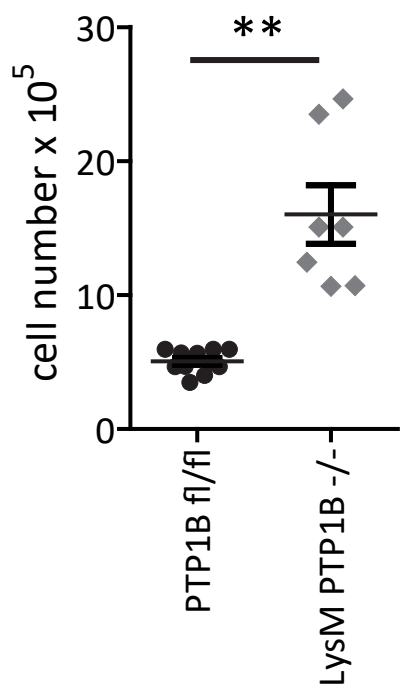

$\mathrm{h}$

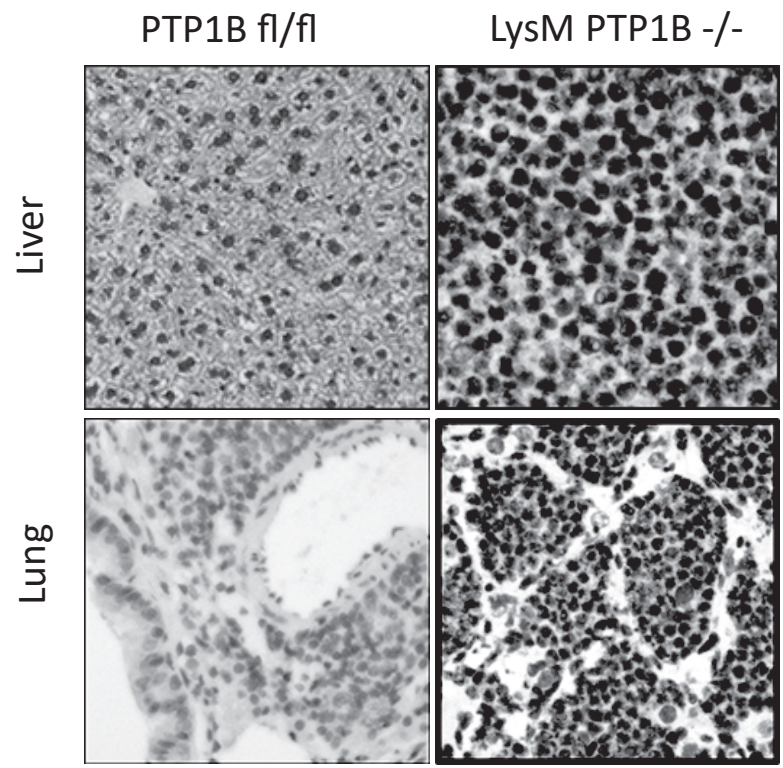




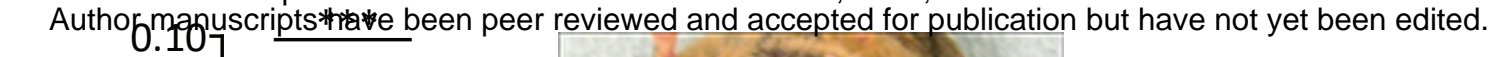

b

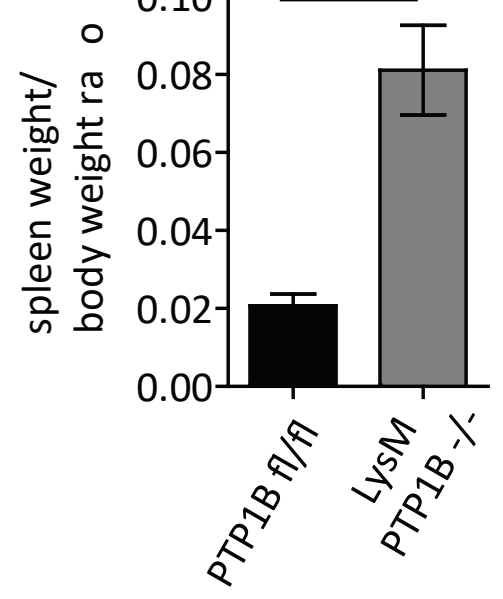

liver

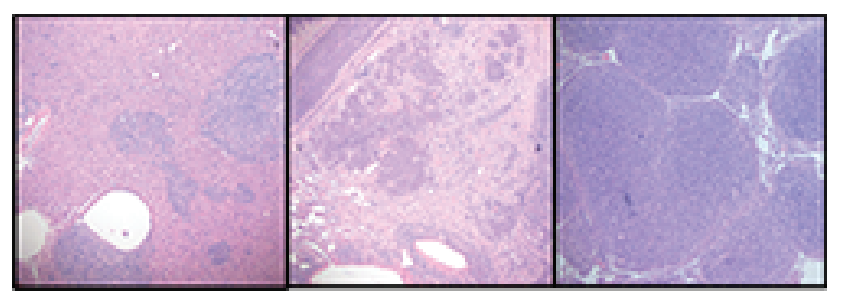

d

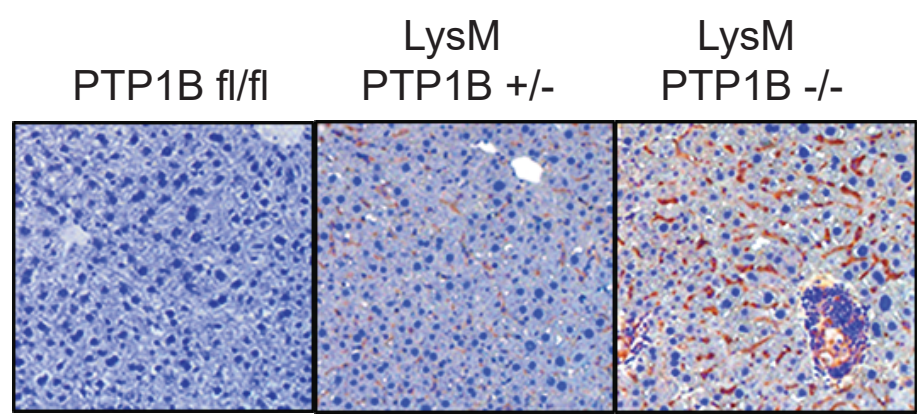

C
LysM
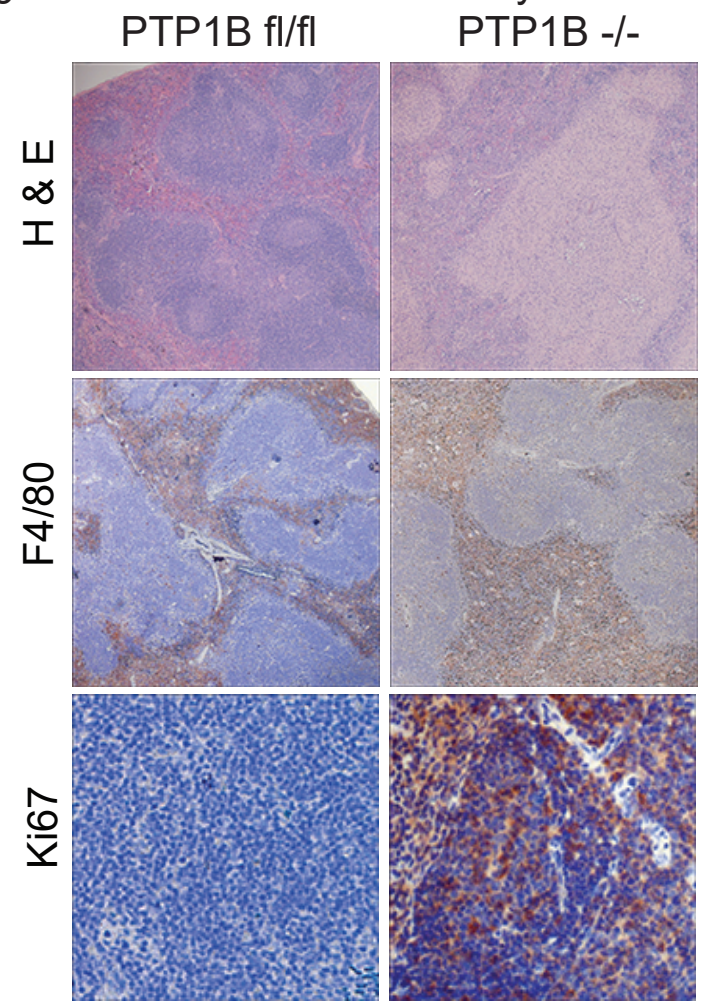

PTP1B -/-

e

liver $f 4 / 80$

liver cd11b $\mathrm{g}$

liver cd68
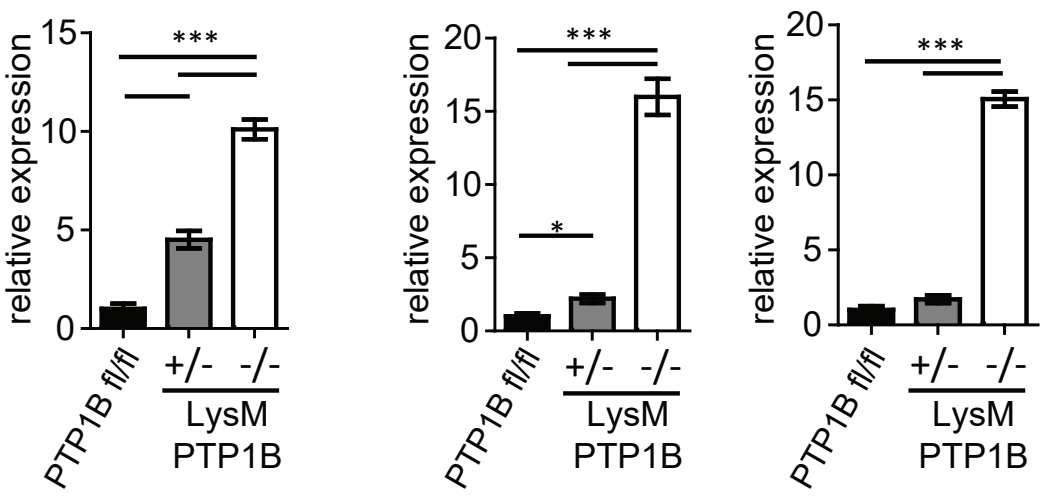

h

\section{Gene ontology - Biological process}

\section{Upregulated}

Transport-

Metabolic process.

Fatty acid metabolic process

Lipid metabolic process

Oxidation-reduction process

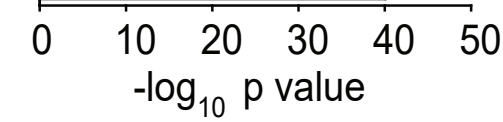

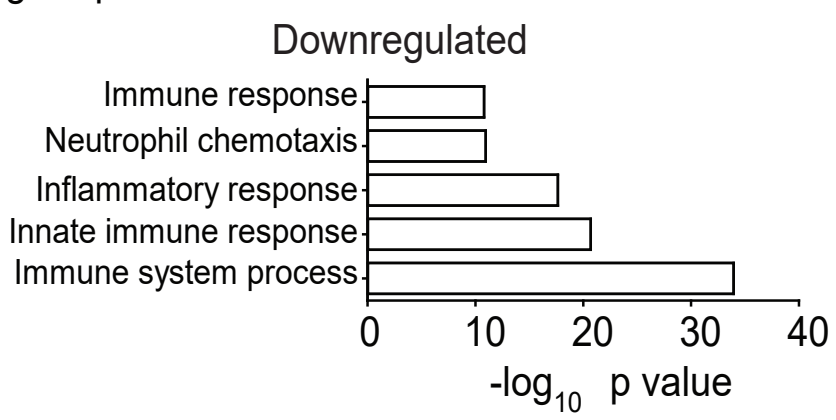

Downregulated 
Author Manuscript Published OnlineFirst.on November 9, 2017; DOI: 10.1158/0008-5472.CAN-17-0946

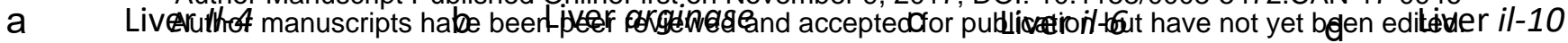
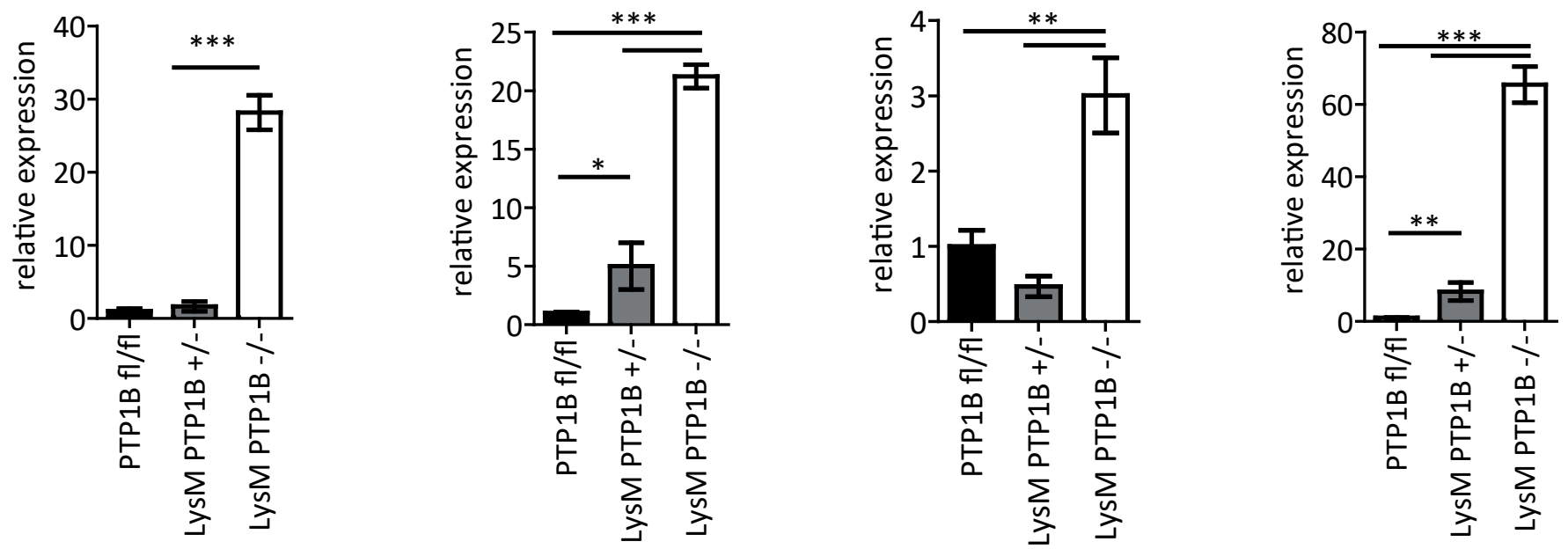

e Spleen il-4

f Spleen arginase

g Spleen il-6

h Spleen il-10
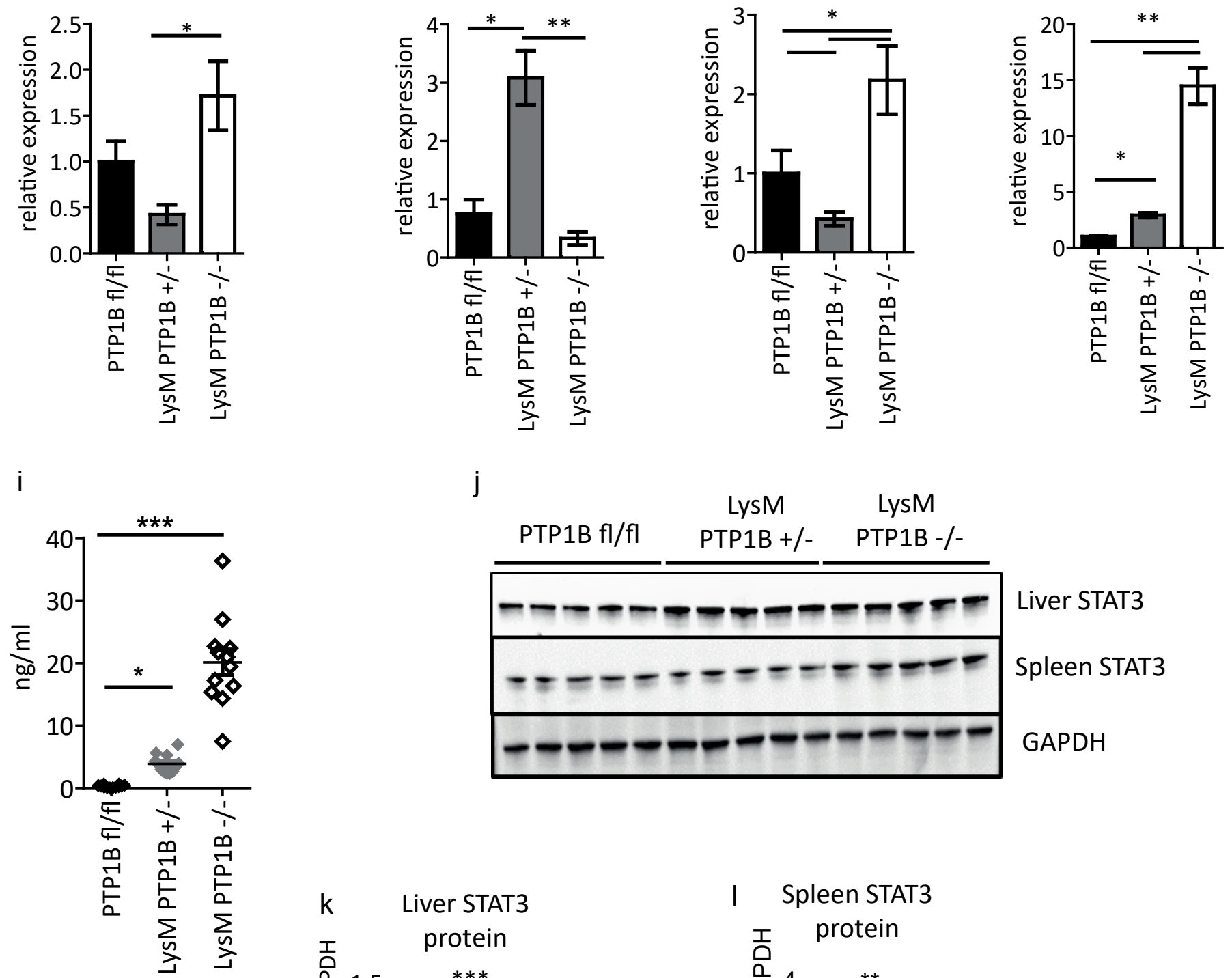

j

LysM LysM
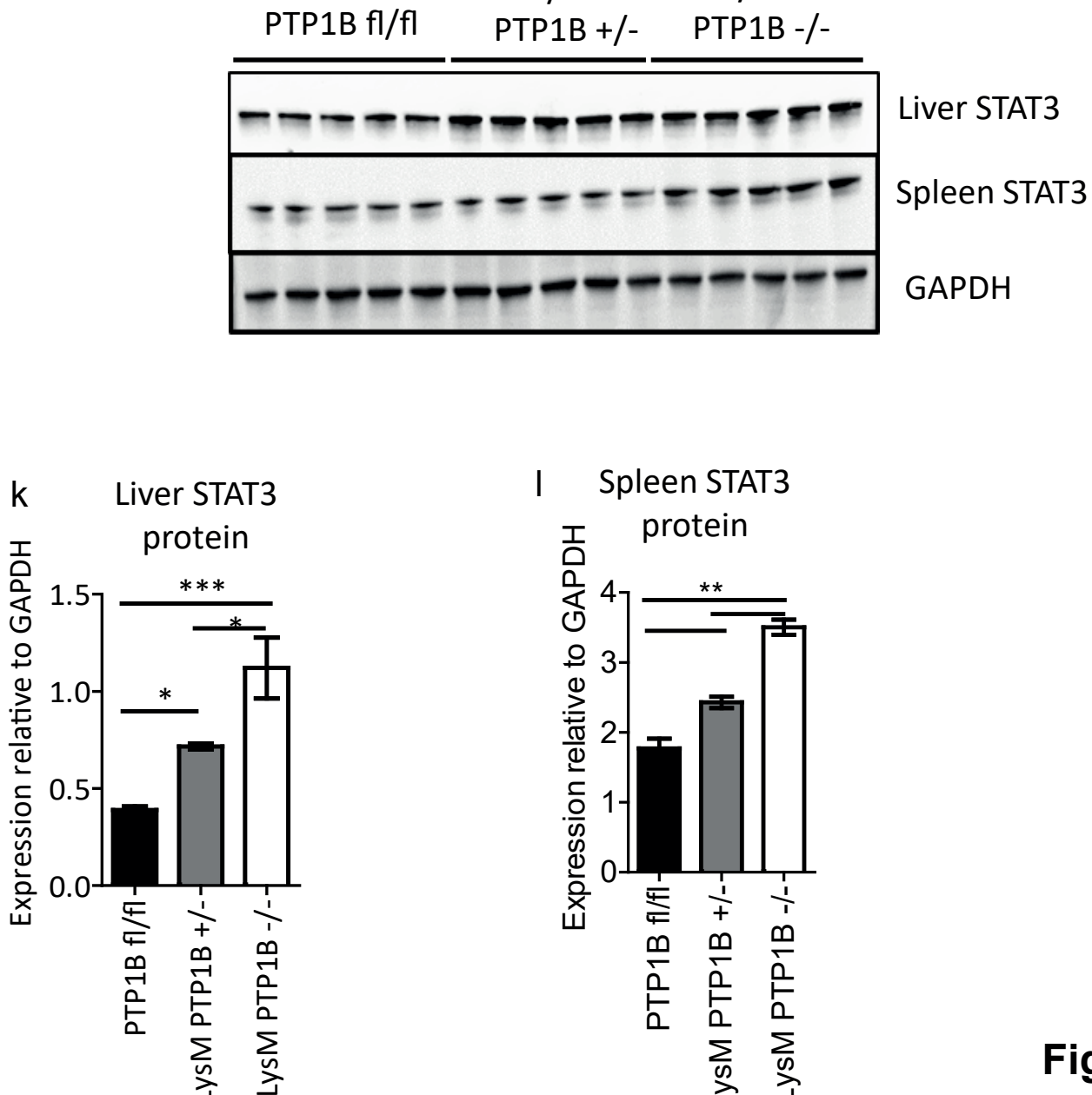

Figure 3 
Author Manuscript Published OnlineFirst on November 9, 2017; DOI: 10.1158/0008-5472.CAN-17-0946

Author manuscripts have been peer reviewed and accepted for publication but have not yet been edited.

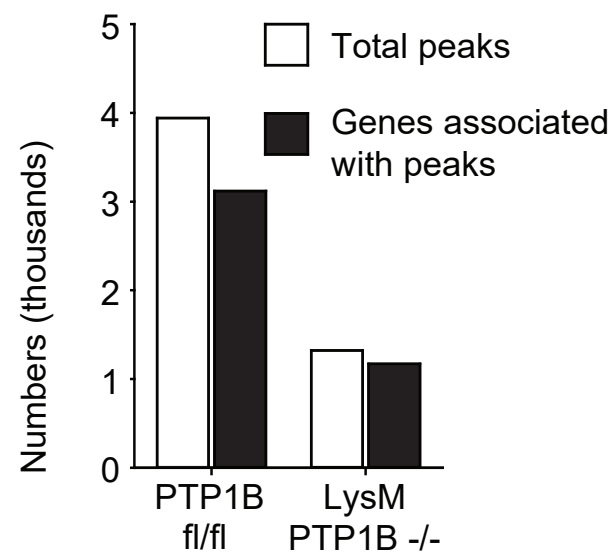

\begin{tabular}{|c|c|c|}
\hline \multirow[b]{2}{*}{ Motif } & \multicolumn{2}{|c|}{ Number of occurances } \\
\hline & $\begin{array}{l}\text { PTP1B } \\
\mathrm{fl} / \mathrm{fl}\end{array}$ & $\begin{array}{c}\text { LysM } \\
\text { PTP1B -/- }\end{array}$ \\
\hline${ }_{\frac{2}{2}}^{2}$ & 1444 & 468 \\
\hline 新- & 224 & 90 \\
\hline
\end{tabular}

C

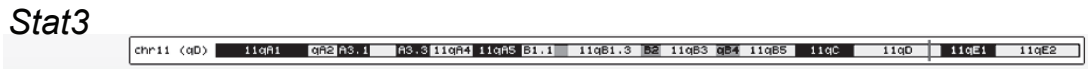

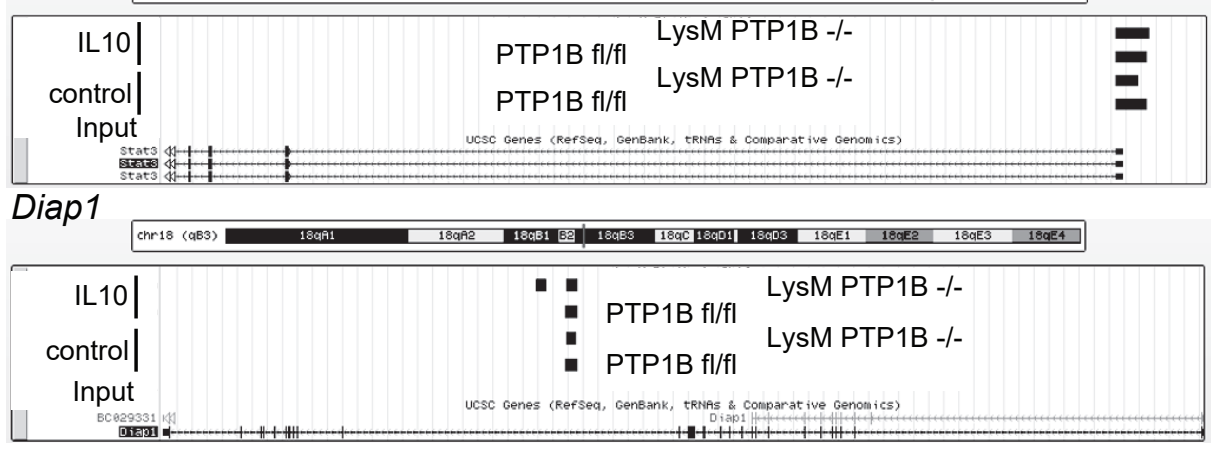

Bc/6

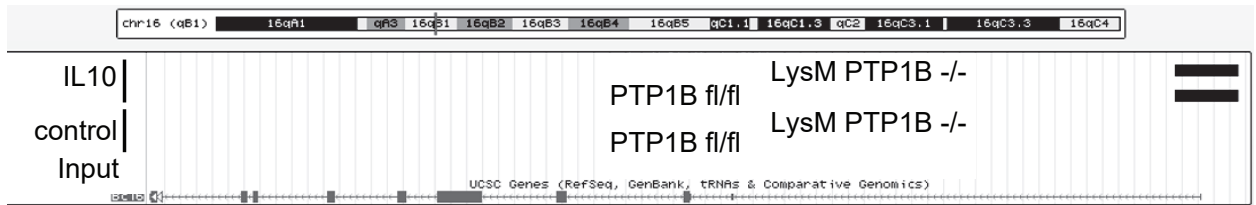

Stat6

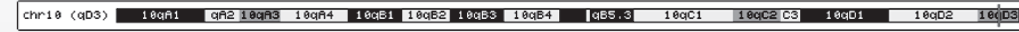

$\begin{array}{r}\hline \begin{array}{c}\text { IL10 } \\ \text { control } \\ \text { Input }\end{array} \\ \text { PTP1B fl/fl LySM PTP1B -/- } \\ \text { PTP1B fl/fl LySM PTP1B -/- } \\ \hline\end{array}$

KIf4

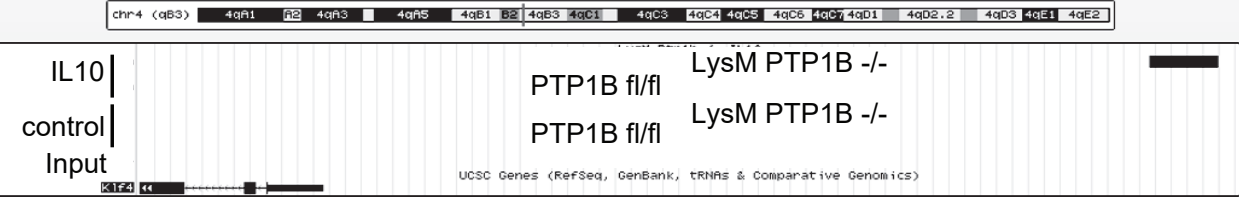

Epas1

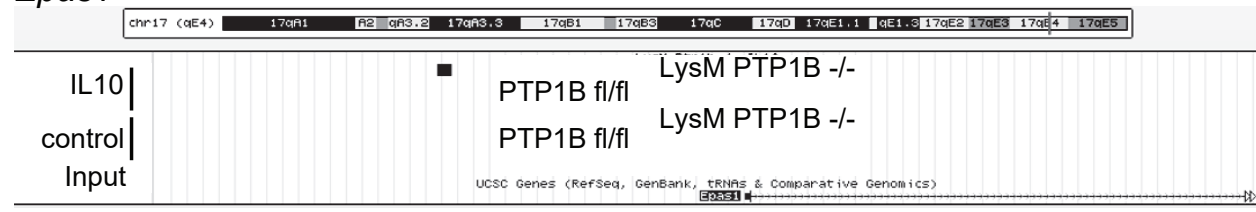

Lims1

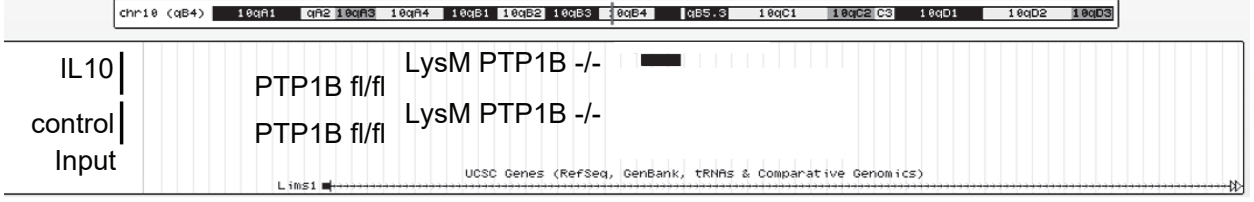




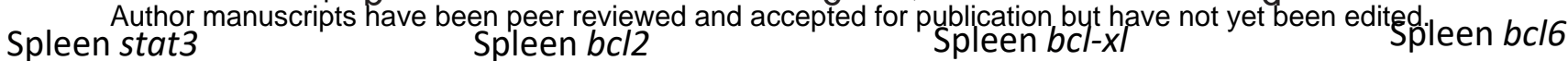

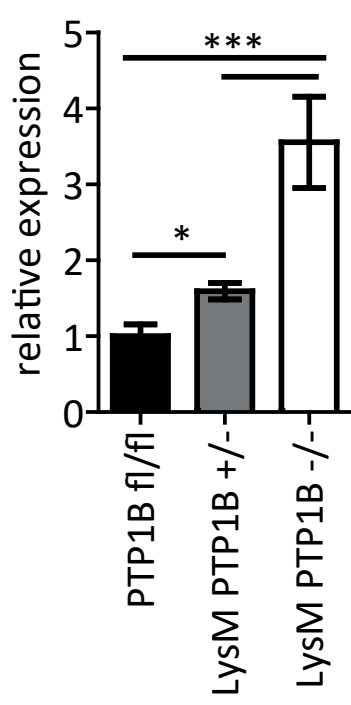

e

Liver stat3

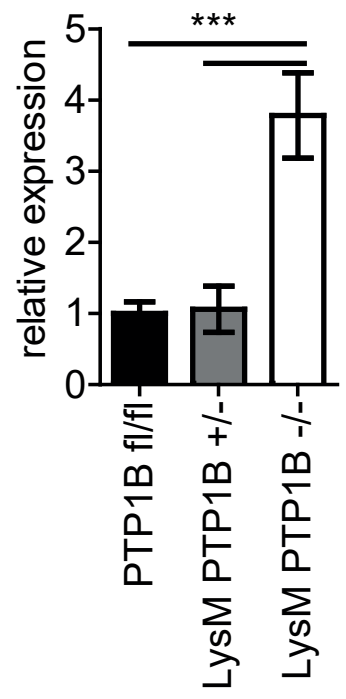

Bone Marrow

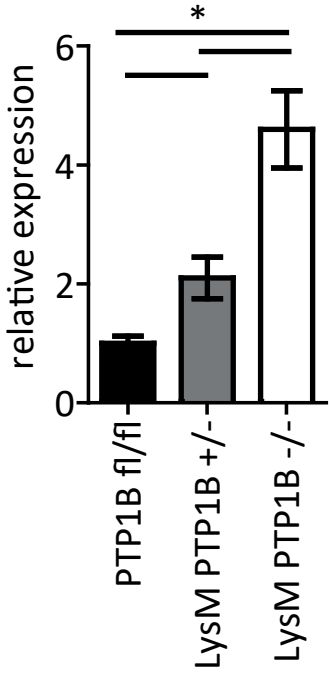

Liver $b c / 2$

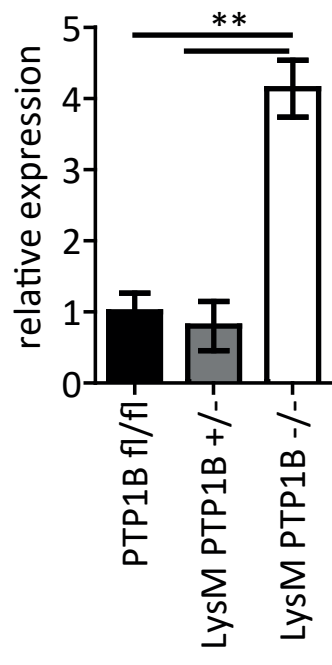

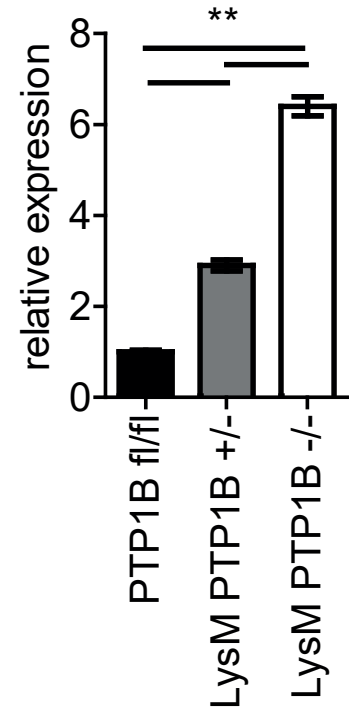

g

Liver $b c l-x \mid$

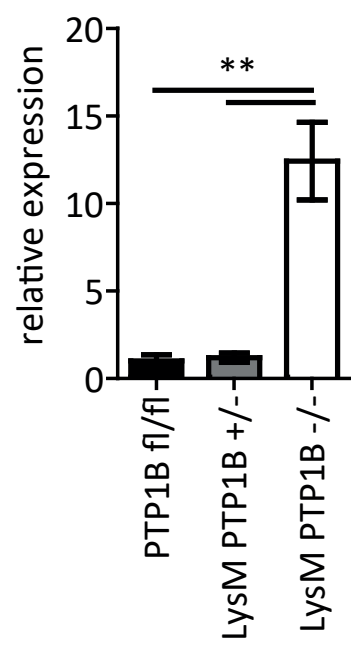

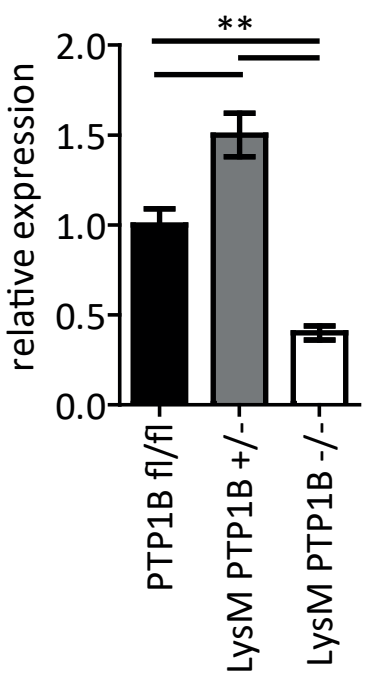

h

Liver $b c l-6$

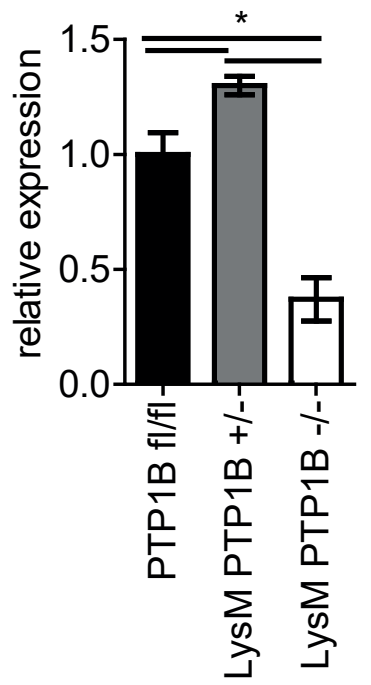

$\underline{\text { Tissues }}$

Circulation

Seeding into tissues

Increased survival

\& proliferation of blast cells
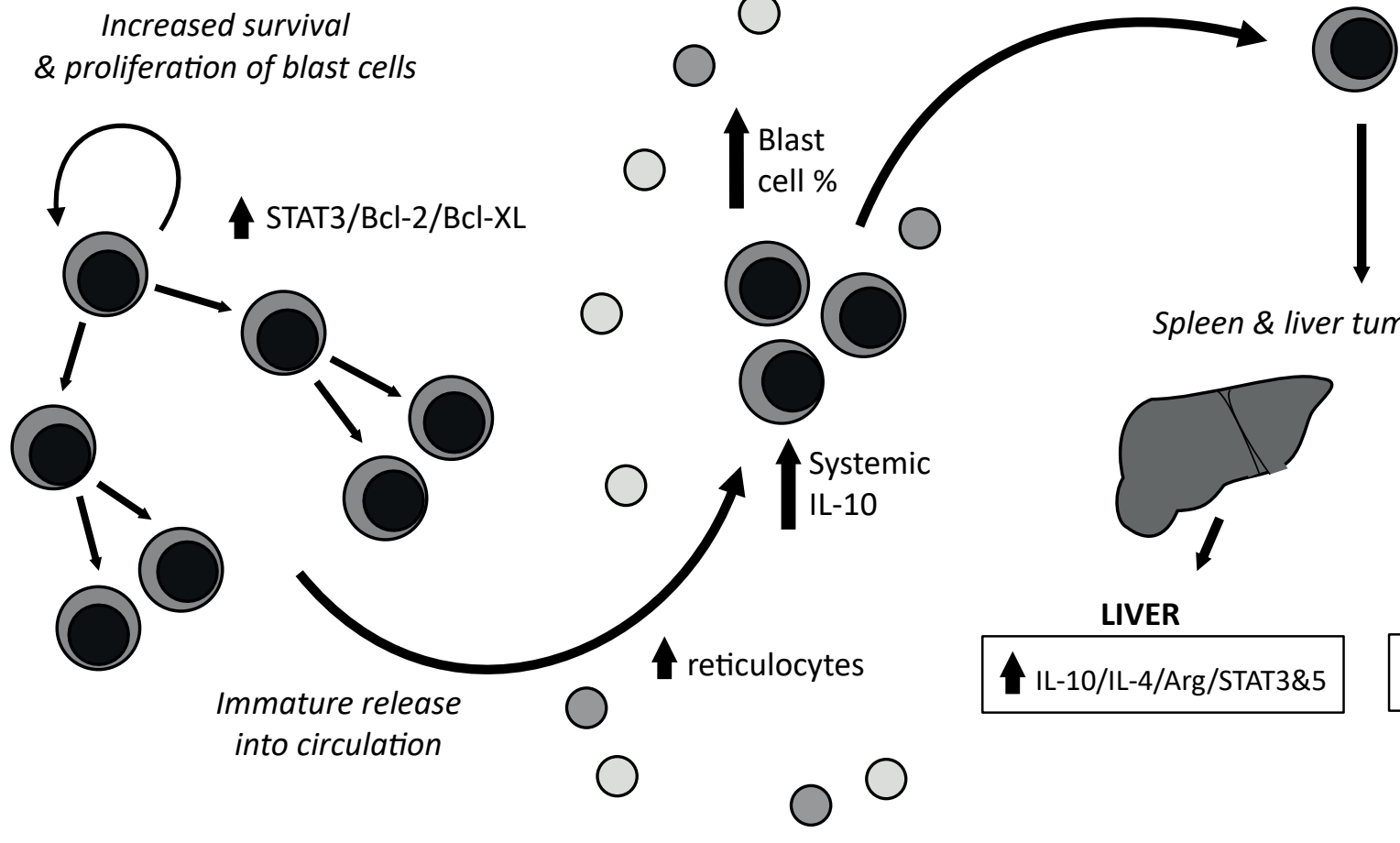

Spleen \& liver tumorigenesis

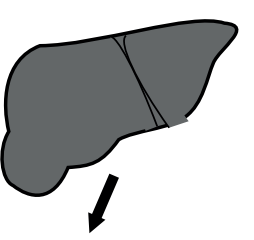

LIVER

IL-10/IL-4/Arg/STAT3\&5

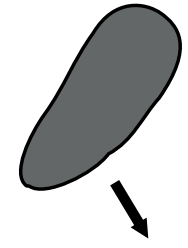

SPLEEN

IL-10/IL-4/STAT3\&5 
Author Manuscript Published OnlineFirst on November 9, 2017; DOI: 10.1158/0008-5472.CAN-17-0946

a

Author manuscripts bave been peev\$Q viewed and accepted for publiagtion but have not yet been edited.

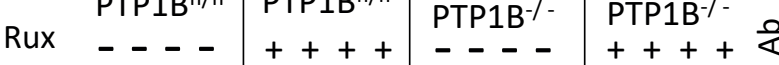

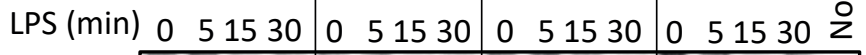

pY-JAK2

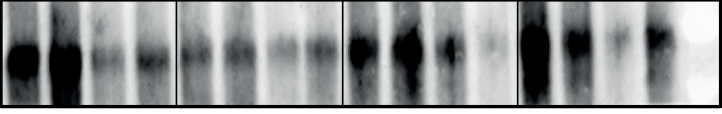

C

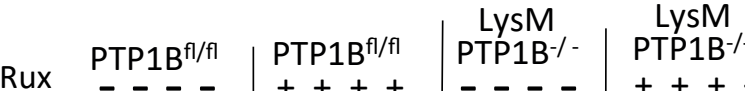

PS (min) - - - $++++\quad---\quad++++$ 060120180060120180060120180060120180

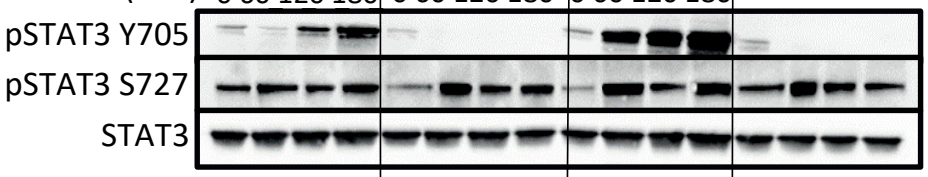

pSTAT5 Y694

STAT5

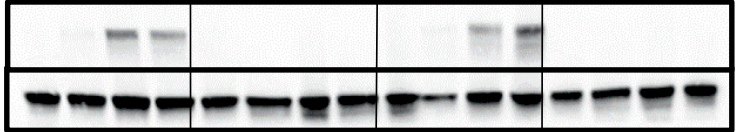

p-mTOR S2448
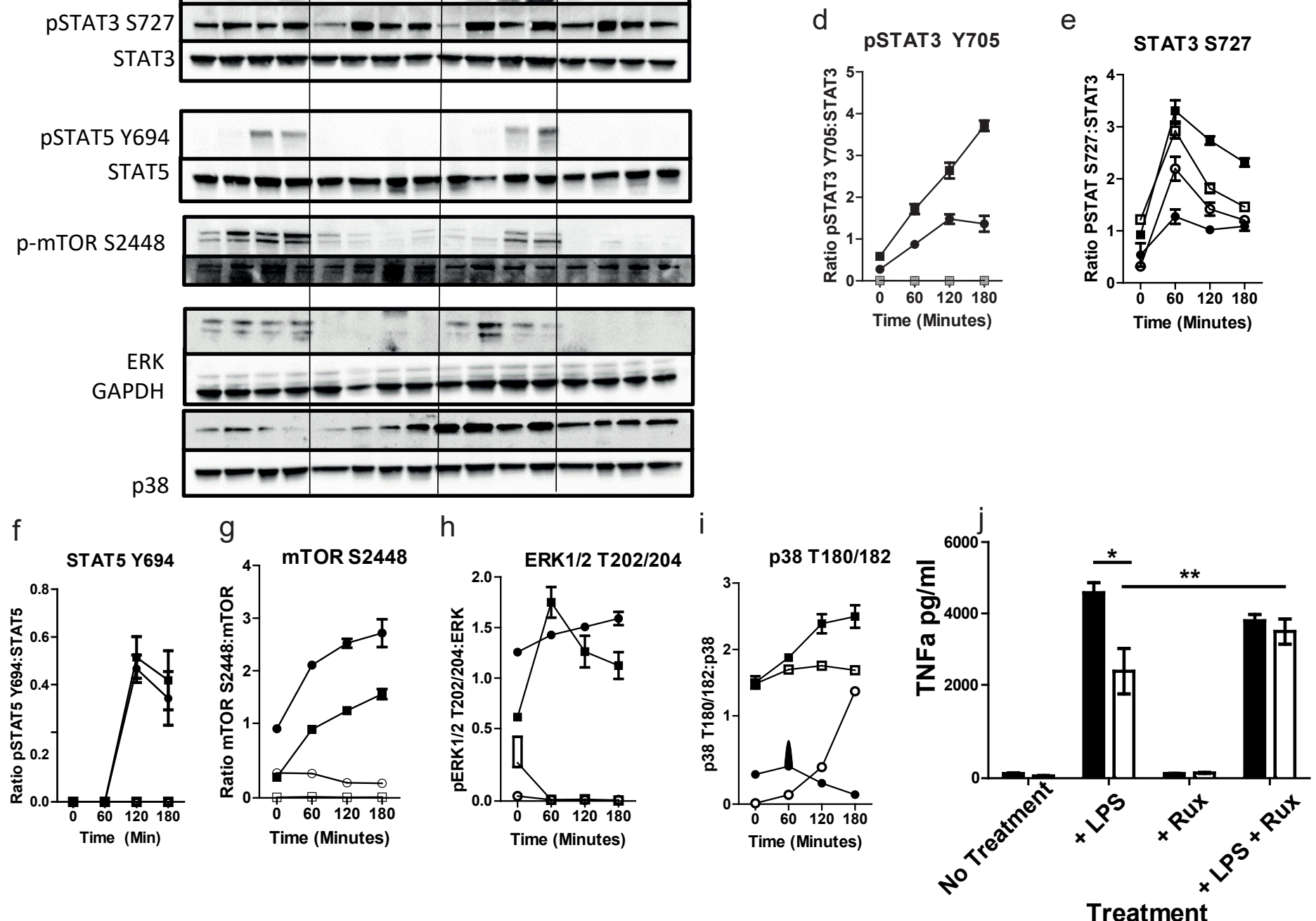

e

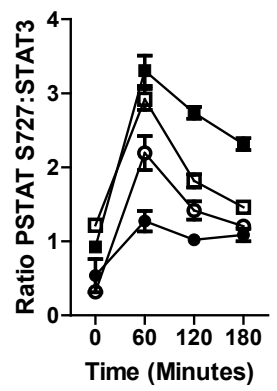

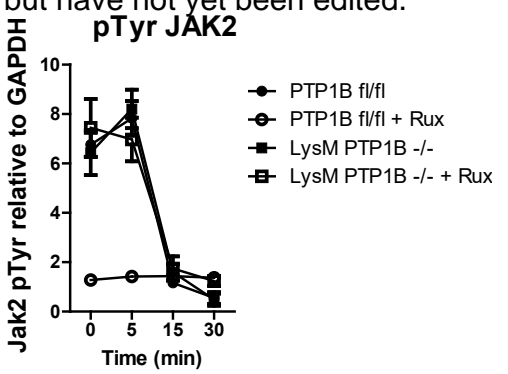

$\mathrm{k}$

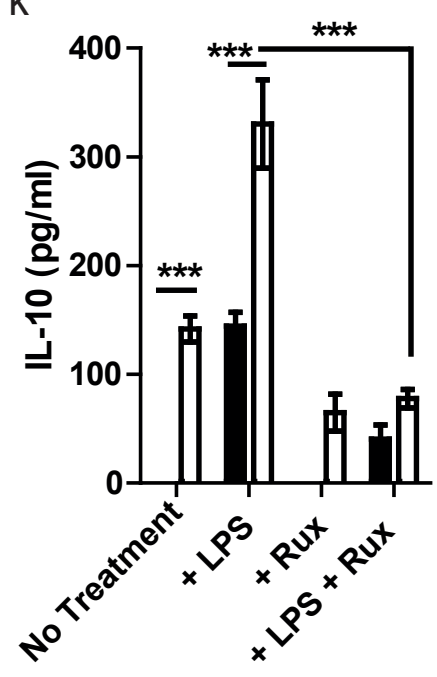

Treatment

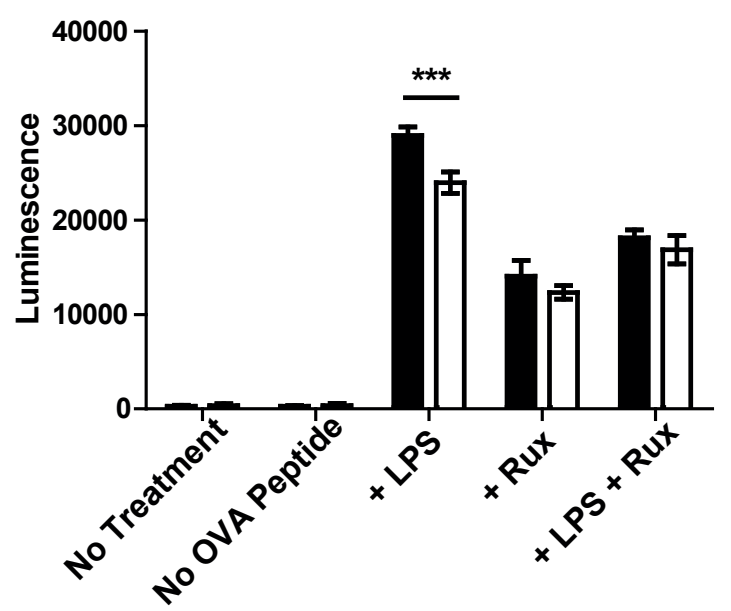

Treatment

m

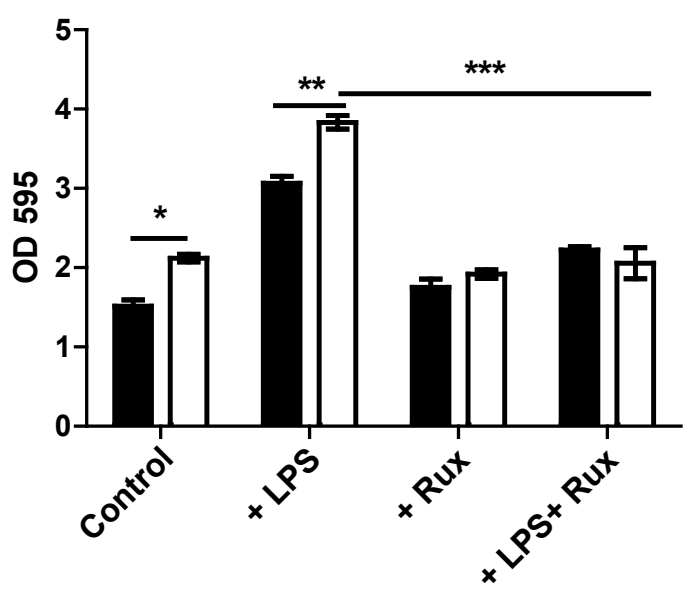

Treatment 


\section{Cancer Research}

AACR

The Journal of Cancer Research (1916-1930) | The American Journal of Cancer (1931-1940)

\section{Deficiency in protein tyrosine phosphatase PTP1B shortens lifespan and leads to development of acute leukemia}

Samantha Le Sommer, Nicola Morrice, Martina Pesaresi, et al.

Cancer Res Published OnlineFirst November 9, 2017.

\section{Updated version Access the most recent version of this article at:} doi:10.1158/0008-5472.CAN-17-0946

Supplementary Access the most recent supplemental material at:

Material http://cancerres.aacrjournals.org/content/suppl/2017/11/09/0008-5472.CAN-17-0946.DC1

Author Author manuscripts have been peer reviewed and accepted for publication but have not yet Manuscript been edited.

E-mail alerts Sign up to receive free email-alerts related to this article or journal.

Reprints and To order reprints of this article or to subscribe to the journal, contact the AACR Publications

Subscriptions Department at pubs@aacr.org.

Permissions To request permission to re-use all or part of this article, use this link http://cancerres.aacrjournals.org/content/early/2017/11/09/0008-5472.CAN-17-0946.

Click on "Request Permissions" which will take you to the Copyright Clearance Center's (CCC) Rightslink site. 